
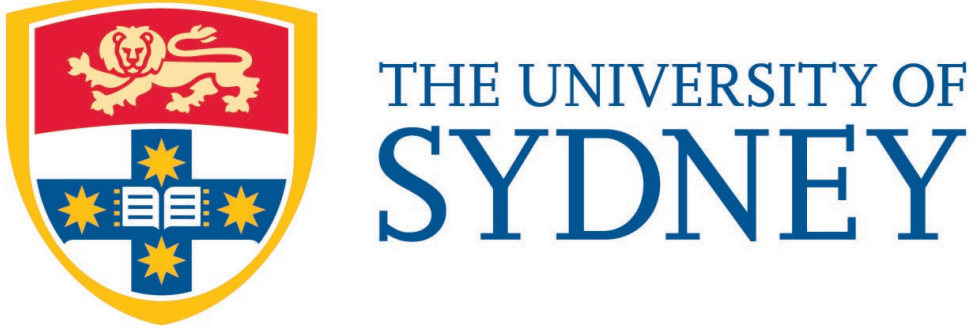

Economics Working Paper Series

$2019-08$

The Effects of Conventional and Unconventional Monetary Policy on Forecasting the Yield Curve

Yunjong Eo and Kyu Ho Kang

November 2019 


\title{
The Effects of Conventional and Unconventional Monetary Policy on Forecasting the Yield Curve*
}

\author{
Yunjong Eo ${ }^{\dagger} \quad$ Kyu Ho Kang ${ }^{\ddagger}$
}

November 13, 2019

\begin{abstract}
We investigate how conventional and unconventional monetary policies affect the dynamics of the yield curve by assessing the performance of individual yield curve models and their mixtures. Out-of-sample forecasts for U.S. bond yields show that the arbitrage-free Nelson-Siegel model and its mixtures with other models perform well in the period of conventional monetary policy, whereas the random walk model outperforms all the other models in the period of unconventional monetary policy. The diminished role of the no-arbitrage restriction in forecasting the yield curve since 2009 can be attributed to unconventional monetary policy, which resulted in low correlations between short- and long-term bond yields and little variation in the short-term rates. During the period of the maturity extension program in 2011-2012, the superiority of the random walk forecasts is more pronounced, reinforcing our finding that the monetary policy framework affects yield curve forecast accuracy.
\end{abstract}

JEL Classification: C11; E43; E47; E52; G12;

Keywords: Quantitative Easing; Operation Twist; Dynamic Nelson-Siegel model; Arbitrage-free term structure model; Random walk model; Markov-switching mixture;

*We thank two anonymous referees, Gianni Amisano, James Bullard, Sung Je Byun, Cem Cakmakh, Marcelle Chauvet, Alex Chudik, Graham Elliott, Domenico Giannone, Massimo Guidolin, Leo Krippner, Taehwy Lee, Michael McCracken, James Morley, Barbara Rossi, Rodrigo Sekkel, Tara Sinclair, Dan Waggoner, Toshiaki Watanabe, Natassa Zervou, and seminar and conference participants at Texas A\&M University, the Federal Reserve Bank of Dallas, the Reserve Bank of New Zealand, University of California Riverside, Hitotsubashi University, the Bank of Korea, the Narodowy Bank Polski Workshop on Forecasting, the International Association for Applied Econometrics conference, the Society for Nonlinear Dynamics and Econometrics Conference, Recent Developments in Financial Econometrics and Applications, EFaB@Bayes 250 Workshop, International Conference on Computational and Financial Econometrics, and Econometric Society Australasian Meeting for useful feedback. Tom Cusbert and Andrew Gaffney provided invaluable research assistance. This research is supported by the FASS Strategic Research Scheme from University of Sydney. All remaining errors are our own. This article is a substantially revised version of an earlier work previously circulated under the title "Forecasting the term structure of interest rates with potentially misspecified models." 


\section{Introduction}

Yield curve forecasts are important for pricing financial assets, optimizing bond portfolios, managing financial risk, and analyzing business cycles. This paper aims to understand how conventional and unconventional monetary policies affect the dynamics of the yield curve by assessing the performance of different yield curve forecasting models in different monetary policy frameworks. The different channels and effects of conventional and unconventional monetary policies on the term structure of interest rates and an increase in the likelihood that further unconventional monetary policy will be necessary in the near future motivate this investigation. ${ }^{1}$

We find that the forecasting performance of various yield curve models (including mixtures thereof) depends on the monetary policy framework. During a period of conventional monetary policy, imposing the no-arbitrage restrictions significantly improves forecasts of the yield curve, though naive forecasts from a random walk model are superior during the period of unconventional monetary policy. We discuss our findings and the effects of the monetary policy frameworks on them in detail below.

We consider three widely used models in this study: (i) the dynamic Nelson-Siegel (DNS) model, (ii) the Arbitrage-free Nelson-Siegel (AFNS) model, and (iii) the random walk (RW) model. Diebold and Li (2006) develop a dynamic version of the Nelson and Siegel (1987) model. The DNS model is a parsimonious factor model in which factors are interpreted as level, slope, and curvature. The affine arbitrage-free model is a bond pricing approach that imposes cross-equation restrictions of no arbitrage opportunities across different maturities and over time. ${ }^{2}$ This approach provides many economically interpretable outcomes, such as the term premium and term structure of real interest rates. We, in particular, consider the arbitrage-free version of the Nelson-Siegel model, because it can be useful to understand the role of the additional cross-equation restrictions of no-arbitrage in forecasting yield curves when compared to the DNS. The RW is often used as a benchmark in terms of forecasting ability in the literature.

\footnotetext{
1 Many studies in the literature find that the natural rate of interest, known as r-star, is very likely to remain low for quite some time. See Laubach and Williams (2016), Hamilton et al. (2016), Pescatori and Turunen (2016), and Christensen and Rudebusch (2017) among others. Taking into account the low interest rate environment, Kiley and Roberts (2017) show that the zero lower bound is binding about 30 or 40 percent of the time using the FRB/US model and a dynamic stochastic general equilibrium model.

${ }^{2}$ For example, see Moench (2008), Christensen, Diebold and Rudebusch (2011), Chib and Kang (2013), Almeida and Vicente (2008), and Carriero and Giacomini (2011) for a class of arbitrage-free models.
} 
However, it is well known that none of the three individual models uniformly outperform the other models for all maturities and forecasting horizons. ${ }^{3}$ The mixed results for out-of-sample (OOS) predictions strongly suggest that these yield curve models may be misspecified, which could be driving our results for the individual models. To counter potential misspecifications, we take three different mixture approaches to integrating model uncertainty and parameter uncertainty: (i) equal weights; (ii) constant weights; and (iii) Markov-switching weights. The mixtures consist of either two or three of these models in addition to individual models. ${ }^{4}$ These forecast combination schemes are in line with the new approaches developed in the econometrics literature, such as linear combinations of predictive densities with constant model weights proposed in Geweke and Amisano (2012) and Markov-switching mixtures of alternative prediction models developed in Waggoner and Zha (2012). ${ }^{5}$ In the case of constant weights, the weights are estimated as constant parameters. A single model can be regarded as a special case of the mixtures.

We forecast monthly U.S. bond yields with eight different maturities at one-, four-, and 12-month forecasting horizons and evaluate the OOS forecasts for one subsample of conventional monetary policy and one subsample of unconventional monetary policy. We choose the best mixture for each maturity at each forecasting horizon based on the mean squared forecast errors (MSFE). That is, for each subsample, there are 24 cases given by eight different maturities times three different forecasting horizons. For the first OOS forecast period of conventional monetary policy, the AFNS or its mixtures with other models outperform other forecasting models in 21 out of 24 cases. On the other hand, during the second OOS

\footnotetext{
${ }^{3}$ For example, Diebold and Li (2006) find that the three-factor DNS outperforms the RW at the onemonth-ahead horizon for short maturities but, for long-term bond yields, the RW dominates the DNS. Zantedeschi, Damien and Polson (2011) argue that the RW forecasts better in the short run whereas at threeand six-month-ahead forecast horizons, the predictions from their DNS with time-varying factor loadings are much improved. Christensen, Diebold and Rudebusch (2011) show that their arbitrage-free affine term structure model produces more accurate six- and 12-month-ahead forecasts than the RW and the DNS.

${ }^{4}$ As an alternative way to account for instability in yield curve models, several recent papers consider Markov-switching models which allow for changes in model parameters in a given model (e.g., Ang and Bekaert (2002), Guidolin and Timmermann (2007), Hevia et al. (2015), and Levant and Ma (2017)). The key aspect that differentiates our work from theirs is that allowing for changes in model weights across different models can be useful in understanding the relative importance of different cross-equation restrictions; for example, no-arbitrage restrictions against simple factor loadings of level, slope, and curvature, as shown in our paper.

${ }^{5}$ Time-varying combination methods are widely studied in the literature using different schemes. For example, see Granger and Newbold (1973), Diebold and Pauly (1987), Deutsch, Granger and Teräsvirta (1994), Elliott and Timmermann (2005), Aiolfi and Timmermann (2006), and Guidolin and Timmermann (2009) among others.
} 
forecast period, which corresponds to the period of unconventional monetary policy, the RW significantly outperforms all possible mixtures and other individual models in 21 out of 24 cases. These results are also confirmed by model confidence sets (MCS) based on Hansen, Lunde and Nason's (2011) procedure.

A natural question arising from our findings is why the no-arbitrage restriction is relevant during the conventional monetary policy period, but not during the unconventional monetary policy period. We argue that these results are attributable to unconventional monetary policy. The AFNS has a small number of factors and their loadings are tightly constrained by the no-arbitrage restriction so that the model is expected to fit to the bond yields and forecast effectively when the yields are highly correlated. The strong positive correlations between the bond yields are associated with conventional monetary policy because changes in the federal fund rate affect the entire path of expected future short-term interest rates and long-term interest rates through this channel. The usefulness of adding the no-arbitrage condition to yield curve models in improving their forecasts is consistent with the findings in the literature, which are based on OOS forecasts for the sample period of conventional monetary policy (see Ang and Piazzesi (2003), Moench (2008), Carriero and Giacomini (2011), and Christensen, Diebold and Rudebusch (2011) among others). In the period of unconventional monetary policy, however, the Fed directly purchased long-term bonds, while short-term yields were constrained by the zero lower bound. This resulted in low correlations between the shortand long-term bond yields and little variation in the short-term bond yields. Thus, the RW forecasts well in this period. We document empirical evidence for changes to the correlation structure and variation in short-term bond yields across two policy periods.

We also plot cumulative squared forecasting errors over time to examine the relative importance of the competing forecasting models at each point in time. We compare the AFNS with the RW to verify the role of the no-arbitrage restrictions against the RW and find that the AFNS forecasts better during the conventional monetary policy period, whereas the RW started forecasting significantly better around late 2008 when unconventional monetary policy began. The superiority of the RW is more pronounced during the maturity extension program in 2011-2012. We conduct the same procedure to compare the Markov-switching mixture of all three models with the RW and find very similar patterns.

Our findings are closely related to the recent literature on unconventional monetary policy and the term structure of interest rates. Swanson and Williams (2014) estimate the 
sensitivity of yields to macroeconomic news and find that yields with six months or less to maturity were severely constrained since early 2009, whereas medium- and longer-term yields were unconstrained by the zero bound. Similarly, Inoue and Rossi (2018) calculate the correlations between Romer and Romer's (2004) monetary policy shocks and yields across different maturities. They document that the correlation was highest for short-term maturities during the conventional monetary policy period, while the correlation was highest for the longest-term maturities during the unconventional monetary policy period. ${ }^{6}$ In addition, Guidolin and Pedio (2019) show that a regime switching DNS model augmented with variables that capture the state of monetary policy outperforms various alternative yield curve models at one-month forecast horizon. While our work is closely related to these findings, our paper differs from those in the literature: we find that no-arbitrage restrictions are less useful for forecasting the yield curve during the unconventional policy period and show why unconventional monetary policy framework leads to this result.

The remainder of the paper is organized as follows. Section 2 describes yield curve models including their mixtures and estimation methods. Section 3 provides the empirical results for the conventional and unconventional monetary policy periods. Section 4 discusses the implications of the monetary policy framework for forecasting the yield curve. Finally, Section 5 concludes the paper.

\section{Yield Curve Prediction}

\subsection{Yield Curve Models}

\subsubsection{Dynamic Nelson-Siegel Model}

In this section, we discuss the three individual yield curve models beginning with the threefactor DNS model. Suppose that the set of maturities is $\left\{\tau_{i}\right\}_{i=1}^{N}$. The $\tau$-period bond yield at time $t$ is denoted by $y_{t}(\tau)$, and the vector of yields with $N$ different maturities at time $t$ is given by

$$
\mathbf{y}_{t}=\left(y_{t}\left(\tau_{1}\right), y_{t}\left(\tau_{2}\right), . ., y_{t}\left(\tau_{N}\right)\right)^{\prime}
$$

\footnotetext{
${ }^{6}$ For the effect of conventional and unconventional monetary policy on interest rates, see Kuttner (2001), Gürkaynak, Sack and Swanson (2005), and Wright (2012) among others.
} 
In the DNS model, $y_{t}(\tau)$ is assumed to be a linear function of the vector of three exogenous latent factors, $\mathbf{x}_{t}=\left(\mathbf{x}_{t}^{L} \mathbf{x}_{t}^{S} \mathbf{x}_{t}^{C}\right)^{\prime}$ :

$$
y_{t}(\tau)=\Lambda(\tau)^{\prime} \mathbf{x}_{t}+\epsilon_{t}(\tau)
$$

where $\Lambda(\tau)=\left(1\left[1-e^{-\tau \lambda} /(\tau \lambda)\right]\left[1-e^{-\tau \lambda} /(\tau \lambda)-e^{-\tau \lambda}\right]\right)^{\prime}$ is the factor loadings and $\epsilon_{t}(\tau)$ is a measurement error. The vector of the latent factors $\mathbf{x}_{t}$ follows a first-order vectorautoregressive process,

$$
\mathbf{x}_{t} \mid \mathbf{x}_{t-1}, \Theta_{N S} \sim \mathcal{N}\left(\kappa+\phi \mathbf{x}_{t-1}, \Omega_{N S}\right)
$$

where $\mathcal{N}(.,$.$) denotes the multivariate normal distribution and \Theta_{N S}$ is the collection of parameters in the DNS model. The decay parameter $\lambda$ is fixed at 0.0607, as in Diebold and Li (2006). ${ }^{7}$

We consider a set of eight different maturities expressed in months, $\left\{\tau_{1}, \ldots, \tau_{8}\right\}=\{3,6,12$, 24, 36, 60, 84, 120\}. For computational convenience, following Bansal and Zhou (2002) and Chib and Kang (2013), we assume that three basis bond yields are observed without errors, while the other yields are observed with normal errors. The three maturities for the basis bond yields are three-month, three-year, and 10-year corresponding to the first, fifth, and eighth maturities $\left\{\tau_{1}, \tau_{5}, \tau_{8}\right\}$, respectively. Let $\mathcal{N}(x \mid m, V)$ denote the multivariate normal density of $x$ with mean $m$ and variance-covariance $V$ and $\mathbf{y}_{t}^{B}=\left(y\left(\tau_{1}\right), y\left(\tau_{5}\right), y\left(\tau_{8}\right)\right)^{\prime}$ and $\mathbf{y}_{t}^{N B}$ denote the vector of the basis and non-basis yields, respectively. Then, given the model specification $\mathcal{M}_{N S}$, the joint density of $\mathbf{y}_{t}$ is obtained as

$$
p\left(\mathbf{y}_{t} \mid Y_{t-1}, \Theta_{N S}, \mathcal{M}_{N S}\right)=\mathcal{N}\left(\mathbf{y}_{t}^{N B} \mid \boldsymbol{\Lambda}_{N B} \mathbf{x}_{t}, \boldsymbol{\Sigma}_{N S}\right) \times \mathcal{N}\left(\mathbf{x}_{t} \mid \kappa+\phi \mathbf{x}_{t-1}, \Omega_{N S}\right) \times\left|\boldsymbol{\Lambda}_{B}^{-1}\right|
$$

where $Y_{t}=\left\{\mathbf{y}_{i}\right\}_{i=1}^{t}$ is the observed yield curve data up to time $t, \boldsymbol{\Lambda}_{B}=\left(\Lambda\left(\tau_{1}\right) \Lambda\left(\tau_{5}\right)\right.$ $\left.\Lambda\left(\tau_{8}\right)\right)^{\prime}$ and $\boldsymbol{\Lambda}_{N B}$ are the factor loadings of the basis and non-basis yields, respectively, $\boldsymbol{\Sigma}_{N S}$ is a diagonal measurement error variance, and then the vector of the factors is given by $\mathbf{x}_{t}=\left(\boldsymbol{\Lambda}_{B}\right)^{-1} \times \mathbf{y}_{t}^{B}$.

\footnotetext{
7 Following Diebold, Rudebusch and Aruoba (2006), we assume normality for measurement errors and shocks to the factors.
} 


\subsubsection{Arbitrage-Free Nelson-Siegel Model}

Let $P_{t}(\tau)$ denote the price of the bond at time $t$ that matures in period $(t+\tau)$. Following Duffie and Kan (1996), we assume that $P_{t}(\tau)$ is an exponential affine function of a vector of three-dimensional factors $\mathbf{f}_{t}$ taking the form

$$
P_{t}(\tau)=\exp \left(-\tau y_{t}(\tau)\right)
$$

where $\mathbf{f}_{t}$ follows the Gaussian mean-reverting first-order autoregression,

$$
\mathbf{f}_{t}=G \mathbf{f}_{t-1}+\eta_{t}, \eta_{t} \sim \mathcal{N}\left(\mathbf{0}, \Omega_{A F}=\mathbf{L} \mathbf{L}^{\prime}\right)
$$

and $y_{t}(\tau)$ is the continuously compounded yield given by

$$
y_{t}(\tau)=a(\tau)+b(\tau)^{\prime} \mathbf{f}_{t}
$$

Suppose that $r_{t}=\delta+\beta^{\prime} \mathbf{f}_{t}$ is the short rate, and $\gamma_{t}=\bar{\gamma}+\Phi \mathbf{f}_{t}$ is the market prices of factor risks. Then, given the stochastic discount factor (SDF),

$$
M_{t, t+1}=\exp \left(-r_{t}-\frac{1}{2} \gamma_{t}^{\prime} \gamma_{t}-\gamma_{t}^{\prime} \mathbf{L}^{-1} \eta_{t+1}\right)
$$

the coefficients, $\{a(\tau), b(\tau)\}_{\tau=0}^{\infty}$ are determined endogenously by the no-arbitrage condition,

$$
P_{t}(\tau)=\mathbb{E}\left[M_{t, t+1} P_{t+1}(\tau-1) \mid \mathbf{f}_{t}\right]
$$

Let $\Theta_{A F}$ denote the model parameters in the affine model $\mathcal{M}_{A F}$. The same three basis bond yields are observed without errors as in the DNS model (2). Then, the conditional density of the yield curve at time $t$ can be expressed as

$$
p\left(\mathbf{y}_{t} \mid Y_{t-1}, \Theta_{A F}, \mathcal{M}_{A F}\right)=\mathcal{N}\left(\mathbf{y}_{t}^{N B} \mid \mathbf{a}_{N B}+\mathbf{b}_{N B} \mathbf{f}_{t}, \mathbf{\Sigma}_{A F}\right) \times \mathcal{N}\left(\mathbf{f}_{t} \mid G \mathbf{f}_{t-1}, \Omega_{A F}\right) \times\left|\mathbf{b}_{B}^{-1}\right|
$$

where $\Sigma_{A F}$ is a diagonal matrix,

$$
\mathbf{a}_{B}=\left(\begin{array}{lll}
a\left(\tau_{1}\right) & a\left(\tau_{5}\right) & a\left(\tau_{8}\right)
\end{array}\right)^{\prime} \text { and } \mathbf{b}_{B}=\left(\begin{array}{lll}
b\left(\tau_{1}\right) & b\left(\tau_{5}\right) & b\left(\tau_{8}\right)
\end{array}\right)^{\prime}
$$


are the intercept term and factor loadings of the basis yields, respectively, $\mathbf{a}_{N B}$ and $\mathbf{b}_{N B}$ are their counterparts for the non-basis yields, and $\mathbf{f}_{t}=\left(\mathbf{b}_{B}\right)^{-1} \times\left(\mathbf{y}_{t}^{B}-\mathbf{a}_{B}\right)$.

For the factor identification, we impose the Nelson-Siegel restrictions:

$$
G^{Q}=G-\mathbf{L} \Phi=\left[\begin{array}{ccc}
1 & 0 & 0 \\
0 & \exp \left(-g^{Q}\right) & g^{Q} \exp \left(-g^{Q}\right) \\
0 & 0 & \exp \left(-g^{Q}\right)
\end{array}\right] \text { and } \beta=(1,1,0)^{\prime}
$$

As shown in Niu and Zeng (2012), as a result of these restrictions, the factor loadings reduce exactly to the form of the DNS factor loading structure. ${ }^{8}$ Finally, following Dai, Singleton and Yang (2007), we set $\delta$ to the sample mean of the short rate, because $\delta$ tends to be estimated inefficiently due to the high persistence of the short rate.

\subsubsection{Random Walk Model}

The third individual prediction model we examine here is the RW model $\mathcal{M}_{R W}$, in which the conditional density of $\mathbf{y}_{t}$ is simply given by

$$
p\left(\mathbf{y}_{t} \mid Y_{t-1}, \Theta_{R W}, \mathcal{M}_{R W}\right)=\mathcal{N}\left(\mathbf{y}_{t} \mid \mathbf{y}_{t-1}, \mathbf{\Sigma}_{R W}\right)
$$

where $\Theta_{R W}=\Sigma_{R W}$ is a diagonal matrix.

\subsection{Model Combinations}

We now briefly illustrate the method used to combine the models using an example of two prediction models, $\mathcal{M}_{1}$ and $\mathcal{M}_{2}$. It is straightforward to extend the framework to combining more than two models in the same way. Let $\Theta_{1}$ and $\Theta_{2}$ be the set of parameters in $\mathcal{M}_{1}$ and $\mathcal{M}_{2}$, respectively. Then, Geweke and Amisano (2011, 2012) study predictive densities of the form

$$
w_{1} \times p\left(\mathbf{y}_{t} \mid Y_{t-1}, \Theta_{1}, \mathcal{M}_{1}\right)+\left(1-w_{1}\right) \times p\left(\mathbf{y}_{t} \mid Y_{t-1}, \Theta_{2}, \mathcal{M}_{2}\right)
$$

where $w_{1} \in[0,1]$ is the model weight on $\mathcal{M}_{1}$.

\footnotetext{
${ }^{8}$ In addition to our specification, we also examined the standard affine model in which $G^{Q}$ is constrained to be a lower triangular matrix. However, we found that the latter model's OOS prediction performance is poorer than that of the AFNS model.
} 
Table 1: The mixture models

\begin{tabular}{|c|c|c|c|}
\hline & DNS & AFNS & RW \\
\hline \multicolumn{4}{|c|}{ Single model } \\
\hline$N$ & & 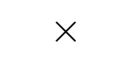 & $x$ \\
\hline$A$ & $x$ & & 상 \\
\hline$R$ & $x$ & & \\
\hline \multicolumn{4}{|c|}{ Equal weight } \\
\hline \multicolumn{4}{|l|}{$N A_{E}$} \\
\hline \multicolumn{4}{|l|}{$N R_{E}$} \\
\hline \multicolumn{4}{|l|}{$A R_{E}$} \\
\hline \multicolumn{4}{|l|}{$N A R_{E}$} \\
\hline \multicolumn{4}{|c|}{ Constant weight } \\
\hline \multicolumn{4}{|l|}{$N A_{C}$} \\
\hline \multicolumn{4}{|l|}{$N R_{C}$} \\
\hline \multicolumn{4}{|l|}{$A R_{C}$} \\
\hline \multicolumn{4}{|l|}{$N A R_{C}$} \\
\hline \multicolumn{4}{|c|}{ Markov-switching weight } \\
\hline$N A_{M S}$ & & & $\times$ \\
\hline$N R_{M S}$ & O & $x$ & \\
\hline$A R_{M S}$ & $x$ & & 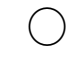 \\
\hline$N A R_{M S}$ & O & O & C \\
\hline
\end{tabular}

Note: The circle $\bigcirc$ indicates an individual model that is included in a mixture model, whereas $\times$ represents a model that is excluded from the specific combination. The mixture model is specified as follows: The model index " $N$ " denotes the DNS model, " $A$ " denotes the AFNS model, and " $R$ " denotes the RW model. The subscript " $E$ " denotes equal weights, " $C$ " denotes constant weights, and " $M S$ " denotes Markov-switching weights. We consider the mixture of two models or all the three models with different weight schemes. For example, " $N R_{E}$ " indicates a mixture of the DNS and the RW with equal weights.

Waggoner and Zha (2012) extend Geweke and Amisano (2011)' approach to allow the model weights to vary over time. They replace $w_{1}$ in (9) with $w_{1, s t} \in[0,1]$ :

$$
w_{1, s_{t}} \times p\left(\mathbf{y}_{t} \mid Y_{t-1}, \Theta_{1}, \mathcal{M}_{1}\right)+\left(1-w_{1, s_{t}}\right) \times p\left(\mathbf{y}_{t} \mid Y_{t-1}, \Theta_{2}, \mathcal{M}_{2}\right)
$$

where $s_{t}$ takes values of either one or two, following a first-order, two-state Markov process with constant transition probabilities, $q_{i j}=\operatorname{Pr}\left[s_{t}=j \mid s_{t-1}=i\right]$ for $i, j=1,2$. By doing so, they consider the case that the relative importance of each of the prediction models can change over time.

Table 1 presents all possible combination models. We first consider each individual model, as well as linear combinations of two or three of the alternatives. We employ three methods 
for determining the model weights: the equal weight, constant weight, and Markov-switching weight. For ease of reference, we use the following shorter model specification indices: " $N$ " denotes the DNS model, " $A$ " denotes the AFNS model, and " $R$ " denotes the RW model. The subscript " $E$ " denotes equal weights, " $C$ " denotes constant weights, and " $M$ " denotes Markov-switching weights. For instance, $N A R_{C}$ is a mixture of the DNS, AFNS, and RW models with constant weights. This implies that the weights are allowed to vary across the models, but are constant over time. In $N A R_{E}$, each of the model weights is fixed at one-third over time. $A R_{M S}$ is a mixture model of the AFNS and RW models with Markov regime-switching weights.

\subsection{Bayesian Estimation}

\subsubsection{Likelihood and Prior}

We denote the model-specific parameters, transition probabilities, and regime-dependent model weight by $\Theta=\left\{\Theta_{1}, \Theta_{2}\right\}, Q=\left\{q_{11}, q_{22}\right\}$, and $w=\left\{w_{1,1}, w_{1,2}\right\}$, respectively. Then, the likelihood function of the yield curves $\left(\mathbf{Y}=\left\{\mathbf{y}_{t}\right\}_{t=1}^{T}\right)$ can be constructed using the predictive density as

$$
\log p(\mathbf{Y} \mid \Theta, Q, w)=\sum_{t=1}^{T} \log p\left(\mathbf{y}_{t} \mid Y_{t-1}, \Theta, Q, w\right)
$$

where the regime $s_{t}$ is integrated out. For more details on constructing the likelihood, refer to the online appendix.

The priors of the parameters for the DNS model and the AFNS model $\left(\Theta_{N S}, \Theta_{A F}\right)$ are set to reflect the a priori belief that the yield curve slopes gently upward and is concave, on average. In particular, the prior of $\Theta_{A F}$ should be chosen carefully, because the bond yields are highly nonlinear in the parameters and the likelihood surface of the AFNS model tends to be irregular. The irregularity of the posterior surface can be more or less pronounced depending on the choice of the prior. Here, following Chib and Ergashev (2009), we choose the prior using a simulation technique. We sample the parameters from the assumed prior and then sample the artificial data given the parameters, repeating this process many times until the mean of the resulting prior-implied unconditional distribution of the yield curve is mildly upward sloping and concave. This simulation-based prior smooths out the many 
local modes of the likelihood surface. Specification of these prior distributions can be found in the online appendix.

\subsubsection{Posterior Simulation}

In combination of the prior with the likelihood, the target distribution to be sampled is the joint posterior distribution of the parameters, factors, and predictive yield curves. Here, we present the posterior sampling scheme for the most general model among the competing ones, namely, the $N A R_{M S}$ model. The others can be estimated as special cases of the $N A R_{M S}$ model by using alternative approaches to determine the weights.

In the Bayesian context, the posterior density for the dynamic mixture model with Markov regime-switching weights is proportional to the product of the likelihood and the joint prior density of the regime indicators $\left(\mathbf{S}=\left\{s_{t}\right\}_{t=1}^{T}\right)$, latent variables $\left(\mathbf{X}=\left\{\mathbf{x}_{t}\right\}_{t=1,2, . ., T}\right.$ and $\left.\mathbf{F}=\left\{\mathbf{f}_{t}\right\}_{t=1,2, . ., T}\right)$, and model parameters $\left(\boldsymbol{\psi}=\left\{\Theta_{N S}, \Theta_{A F}, \Theta_{R W}, Q, w\right\}\right)$.

The posterior density is given by

$$
\pi(\boldsymbol{\psi}, \mathbf{X}, \mathbf{F}, \mathbf{S} \mid \mathbf{Y}) \propto f(\mathbf{Y} \mid \boldsymbol{\psi}, \mathbf{X}, \mathbf{F}, \mathbf{S}) \times f(\mathbf{X}, \mathbf{F} \mid \boldsymbol{\psi}) \times p(\mathbf{S} \mid \boldsymbol{\psi}) \times \pi(\boldsymbol{\psi})
$$

where $\pi(\boldsymbol{\psi})$ is the prior density of the parameters, and $p(\mathbf{S} \mid \boldsymbol{\psi})$ is the prior density of the regime indicators, given the parameters where it is specified as a discrete two-state Markov-switching process. In addition, $f(\mathbf{X}, \mathbf{F} \mid \mathbf{S}, \boldsymbol{\psi})$ is the prior density of the factors and $f(\mathbf{Y} \mid \boldsymbol{\psi}, \mathbf{X}, \mathbf{F}, \mathbf{S})$ is the likelihood function.

Our objective is to simulate the posterior distribution of $(\boldsymbol{\psi}, \mathbf{X}, \mathbf{F}, \mathbf{S})$ conditioned on the observed yield curves $\mathbf{Y}$. Because the joint posterior distribution (11) is not analytically tractable, we rely on an MCMC simulation. The parameters, factors, regimes, and predictive yield curves are recursively sampled, as follows.

Algorithm: $M C M C$ sampling

- Step 1: Sample $\Theta_{N S}, \Theta_{A F}, \Theta_{R W}, w, Q \mid \mathbf{Y}$.

- Step 1(a): Sample $\Theta_{N S}, \Theta_{A F}, \Theta_{R W}, w \mid \mathbf{Y}, Q$.

- Step 1(b): Sample $Q \mid \mathbf{Y}, \mathbf{S}, \Theta_{N S}, \Theta_{A F}, \Theta_{R W}, w$.

- Step 2: Sample $\mathbf{S} \mid \mathbf{Y}, \boldsymbol{\psi}$. 
- Step 3: Sample $\mathbf{X} \mid \mathbf{Y}, \boldsymbol{\psi}$ and $\mathbf{F} \mid \mathbf{Y}, \boldsymbol{\psi}$.

- Step 4: Sample $\left\{\mathbf{y}_{T+h}\right\}_{h=1}^{H} \mid \mathbf{Y}, \mathbf{X}, \mathbf{F}, \mathbf{S}, \boldsymbol{\psi}$.

For the details of each MCMC step, see the online appendix. We run the MCMC simulation for 10,000 iterations after 1,000 burn-in iterations.

\section{The Effects of Monetary Policy on Forecasting the Yield Curve}

We now examine how the monetary policy regime affects the ability of the different models to forecast the yield curve using the OOS forecast performance. In particular, we concentrate on identifying the best models during conventional and unconventional monetary policy periods.

\subsection{Data and Forecasting Evaluation}

Our data comprise monthly yields on U.S. government bonds. The yields are calculated for bonds with maturities of $3,6,12,24,36,60,84$ and 120 months. The sample period is from February 1994 to December 2013. Our last forecast sample period is December 2013, when the Fed officially announced that it would begin to taper its bond purchases from January 2014. The announcement would substantially alter the effects of unconventional monetary policy on the yield curve, especially for long-term bonds as investors expected the Fed to reduce its demand for these bonds.

For the model comparison, we calculate the MSFE values using a rolling window estimation with a fixed number of observations. The window size is 120 months $(m=120)$, and the forecasts are made for eight maturities at horizons of $h=1,4$, and 12 months ahead. The first estimation sample covers the period February 1994 to January 2004, and the corresponding OOS forecasts are the yields for February 2004, May 2004, and January 2005 $(h=1,4,12)$. We then move the estimation window sample period and the OOS forecasts forward by one month. Thus, the next estimation sample period is March 1994 to February 2004, and the corresponding OOS forecasts are the yields for March 2004, June 2004, and February 2005, and so on. This procedure is repeated 108 times $(n=108)$, where the last 
Table 2: Rolling windows and out-of-sample forecasting periods

\begin{tabular}{lccccc}
\hline & & Rolling window sample & \multicolumn{3}{c}{ Out-of-sample forecasts } \\
& & for estimation & $\mathrm{h}=1$ & $\mathrm{~h}=4$ & $\mathrm{~h}=12$ \\
\hline \multirow{3}{*}{$\begin{array}{l}\text { Conventional } \\
\text { Policy }\end{array}$} & 2 & Feb. 1994- Jan. 2004 & Feb. 2004 & May 2004 & Jan. 2005 \\
& & Mar. 1994 - Feb. 2004 & Mar. 2004 & Jun. 2004 & Feb. 2005 \\
& & $\vdots$ & & $\vdots$ & \\
& 54 & Jul. 1997 - Jun. 2008 & Jul. 2008 & Oct. 2008 & Jun. 2009 \\
Unconventional & 55 & Aug. 1997- Jul. 2008 & Aug. 2008 & Nov. 2008 & Jul. 2009 \\
Policy & & $\vdots$ & & $\vdots$ & \\
& 107 & Dec. 2002 - Nov. 2012 & Dec. 2012 & Mar. 2013 & Nov. 2013 \\
& 108 & Jan. 2003 - Dec. 2012 & Jan. 2013 & Apr. 2013 & Dec. 2013 \\
\hline
\end{tabular}

Note: Given a rolling window sample, we produce yield curve forecasts for each maturity and forecast horizon pair.

estimation sample period is January 2012 to December 2012, and the corresponding OOS forecasts are the yields for January 2013, April 2013, and December 2013. We conduct forecasting evaluations to understand the effects of monetary policy on forecasting the yield curves using one subsample during the conventional monetary policy period and one subsample for the unconventional monetary policy period. The first round of quantitative easing, also called QE1, was announced on November 25, 2008 and we set November 2008 to the last OOS forecast at the forecasting horizon of $h=4$ for the first subsample associated with conventional monetary policy. Thus, both subsamples have the same forecasting evaluation sample size of 54 . The details about our rolling widow and forecasts pairs are shown in Table 2 .

We forecast the yield curves for each pair of a maturity and a forecast horizon and evaluate the predictive accuracy using two methods: (i) best model selection and (ii) MCS proposed by Hansen, Lunde and Nason (2011) based on the MSFE. ${ }^{9}$ The MCS is constructed such that it contains the best models with a given level of confidence and does not assume that a particular model is the true model. As such, it is useful when considering that the models contained in the model prediction set are potentially misspecified, as in our study.

\footnotetext{
${ }^{9}$ Throughout this paper, we evaluate the forecasting accuracy of multiple individual bond yields rather than that of the yield curve to determine the maturity-specific forecasting performance of the models and to compare the results with those in the literature.
} 


\subsection{Mean Squared Forecast Error Results}

We produce the forecasts using a rolling window estimation scheme. Let $T$ be the total sample size and $m$ be the estimation window. We formulate the $h$-step-ahead forecasts for the $\tau$-month bond yield at time $t$ using the data $\mathbf{Y}_{t-m+1: t}=\left(Y_{t-m+1}, \ldots, Y_{t-1}, Y_{t}\right)$. Then, we compare these forecasts $y_{t+h}(\tau)$ to the realization $y_{t+h}^{o}(\tau)$. Iterating this procedure for $t=(T-h-n+1), \ldots,(T-h)$ produces $n$ OOS forecasts and relative forecast errors. Let $\overline{y_{i, t+h}(\tau)}$ denote the posterior mean of $y_{i, t+h}(\tau)$, conditional on a combination of model $i$ and data $\mathbf{Y}_{t-m+1: t}$. Given each combination model $i$ and the data, the MSFE of the $h$-monthahead bond yield with $\tau$ months to maturity, denoted by $M S F E_{i}(\tau, h)$, is given by

$$
\operatorname{MSFE} E_{i}(\tau, h)=\frac{1}{n} \sum_{t=T-h-n+1}^{T-h} L_{i, t}(\tau, h),
$$

where the loss function is given by $L_{i, t}(\tau, h)=\left[y_{t+h}^{o}(\tau)-\overline{y_{i, t+h}(\tau)}\right]^{2}$. We choose the best prediction models that produce the smallest MSFE value for each pair of a maturity $\tau$ and a forecast horizon $h, M S F E(\tau, h)$.

Table 3 reports the best models that achieve the smallest MSFE values for the two OOS forecast subsamples in addition to best models over both conventional and unconventional monetary policy periods. In addition, Tables 4- 6 present the MSFEs across all the maturities at one-, four- and 12-month-ahead forecasting horizons, respectively. ${ }^{10}$

The forecasting performance evaluation results show that the best models are markedly different during the periods of conventional and unconventional monetary policy. For the conventional monetary policy period, the best model includes the AFNS in 21 cases either as part of a mixture or individually (that is, as $N A R_{M S}, N A R_{E}, N A_{C}, N A R_{C}$, or $A$ ). In particular, the AFNS dominates the other competing models for short- and medium-term maturities at the 12-month-ahead forecast horizon. A mixture of two or three models is selected as the best model in 15 out of 24 cases. These results imply that the no-arbitrage restriction appears to be useful in improving forecasting accuracy during the conventional monetary policy period. Also, we find that taking mixtures of competing models improves forecasting performance.

However, during the unconventional monetary policy period the RW model seems to

\footnotetext{
10 See the online appendix for the full sample forecasting results.
} 
Table 3: Best models

\begin{tabular}{rcccccccc}
\hline & $3 \mathrm{~m}$ & $6 \mathrm{~m}$ & $12 \mathrm{~m}$ & $24 \mathrm{~m}$ & $36 \mathrm{~m}$ & $60 \mathrm{~m}$ & $84 \mathrm{~m}$ & $120 \mathrm{~m}$ \\
\hline 1-month-ahead & $N A R_{M}$ & $N A R_{E}$ & $N A R_{E}$ & $N A_{C}$ & $N A R_{M S}$ & $N A R_{M S}$ & $R$ & $N A_{C}$ \\
4-month-ahead & $N A R_{E}$ & $N A R_{E}$ & $N A R_{E}$ & $N A R_{E}$ & $N A R_{M S}$ & $N A R_{M S}$ & $N A R_{C}$ & $N A_{C}$ \\
12-month-ahead & $A$ & $A$ & $A$ & $A$ & $A$ & $A$ & $R$ & $R$ \\
\hline
\end{tabular}

(a) Conventional monetary policy period

\begin{tabular}{rcccccccc}
\hline & $3 \mathrm{~m}$ & $6 \mathrm{~m}$ & $12 \mathrm{~m}$ & $24 \mathrm{~m}$ & $36 \mathrm{~m}$ & $60 \mathrm{~m}$ & $84 \mathrm{~m}$ & $120 \mathrm{~m}$ \\
\hline 1-month-ahead & $R$ & $N$ & $N R_{M}$ & $R$ & $R$ & $R$ & $R$ & $N R_{E}$ \\
4-month-ahead & $R$ & $R$ & $R$ & $R$ & $R$ & $R$ & $R$ & $R$ \\
12-month-ahead & $R$ & $R$ & $R$ & $R$ & $R$ & $R$ & $R$ & $R$ \\
\hline
\end{tabular}

(b) Unconventional monetary policy period

\begin{tabular}{rcccccccc}
\hline & $3 \mathrm{~m}$ & $6 \mathrm{~m}$ & $12 \mathrm{~m}$ & $24 \mathrm{~m}$ & $36 \mathrm{~m}$ & $60 \mathrm{~m}$ & $84 \mathrm{~m}$ & $120 \mathrm{~m}$ \\
\hline 1-month-ahead & $R$ & $N R_{E}$ & $N R_{M S}$ & $R$ & $R$ & $R$ & $R$ & $N R_{M S}$ \\
4-month-ahead & $R$ & $N$ & $N$ & $R$ & $R$ & $R$ & $R$ & $N A_{C}$ \\
12-month-ahead & $R$ & $N R_{M S}$ & $R$ & $R$ & $R$ & $R$ & $R$ & $R$ \\
\hline
\end{tabular}

(c) Both conventional and unconventional monetary policy periods

Note: The model indicators $N, A$, and $R$ denote the DNS model, AFNS model, and RW model, respectively. The subscripts $E, C$, and $M S$ denote equal weights, constant weights, and Markov-switching weight combinations, respectively. The forecasts for conventional monetary policy are made in January 2004 to July 2008 while those for unconventional monetary policy are made in August 2008 to December 2012. Finally, the forecasts for conventional and unconventional monetary policy are made in both periods, ranging from January 2004 to December 2012. For more details on the periods of conventional and unconventional policy, see Table 2 .

perform best among the individual and mixture models. The RW model outperforms the other combination models in 21 of 24 cases. In particular, the RW model produces the most accurate point forecasts for bond yields of 3, 24, 36, 60, and 84 months at all forecast horizons. The superior performance of the RW model during this period can be attributed to the advantage it has in considering the possibility of structural changes in U.S. yield curve dynamics. Because the results for the second half of the OOS forecast periods dominate those for the first half of the OOS forecast periods, the RW model appears to be the best model in most cases for samples that include both periods.

\subsection{Model Confidence Set Results}

Although the best model selection procedure based on MSFE values in the previous section is simple and straightforward, choosing one particular model may disregard other models 
Table 4: Mean squared forecasting errors and MCS p-values for one-month-ahead forecasts

\begin{tabular}{|c|c|c|c|c|c|c|c|c|c|c|c|c|c|c|c|c|}
\hline & \multicolumn{2}{|c|}{3 months } & \multicolumn{2}{|c|}{6 months } & \multicolumn{2}{|c|}{12 months } & \multicolumn{2}{|c|}{24 months } & \multicolumn{2}{|c|}{36 months } & \multicolumn{2}{|c|}{60 months } & \multicolumn{2}{|c|}{84 months } & \multicolumn{2}{|c|}{120 months } \\
\hline & $p_{M C S}$ & MSFE & $p_{M C S}$ & MSFE & $p_{M C S}$ & MSFE & $p_{M C S}$ & MSFE & $p_{M C S}$ & MSFE & $p_{M C S}$ & MSFE & $p_{M C S}$ & MSFE & $p_{M C S}$ & MSFE \\
\hline \multicolumn{17}{|c|}{ Single model } \\
\hline$N$ & 0.000 & 0.097 & 0.015 & 0.096 & 0.058 & 0.071 & 0.002 & 0.086 & 0.019 & 0.094 & 0.058 & 0.081 & 0.143 & 0.069 & 0.018 & 0.049 \\
\hline$A$ & 0.248 & 0.088 & 0.108 & 0.080 & 0.128 & 0.066 & 0.054 & 0.082 & 0.172 & 0.090 & 0.058 & 0.086 & 0.011 & 0.083 & 0.013 & 0.049 \\
\hline$R$ & 0.081 & 0.096 & 0.108 & 0.082 & 0.010 & 0.078 & 0.002 & 0.086 & 0.172 & 0.092 & 0.178 & 0.074 & 1.000 & 0.062 & 0.013 & 0.050 \\
\hline \multicolumn{17}{|c|}{ Equal weight } \\
\hline$N A_{E}$ & 0.110 & 0.095 & 0.108 & 0.079 & 0.435 & 0.061 & 0.054 & 0.084 & 0.000 & 0.106 & 0.058 & 0.082 & 0.000 & 0.117 & 0.000 & 0.059 \\
\hline$N R_{E}$ & 0.000 & 0.097 & 0.040 & 0.086 & 0.010 & 0.072 & 0.000 & 0.088 & 0.172 & 0.091 & 0.113 & 0.076 & 0.314 & 0.065 & 0.007 & 0.050 \\
\hline$A R_{E}$ & 0.110 & 0.095 & 0.108 & 0.082 & 0.058 & 0.071 & 0.002 & 0.085 & 0.172 & 0.089 & 0.178 & 0.074 & 0.143 & 0.068 & 0.018 & 0.049 \\
\hline$N A R_{E}$ & 0.224 & 0.089 & 1.000 & 0.073 & 1.000 & 0.061 & 0.054 & 0.083 & 0.000 & 0.097 & 0.113 & 0.076 & 0.003 & 0.086 & 0.004 & 0.055 \\
\hline \multicolumn{17}{|c|}{ Constant weight } \\
\hline$N A_{C}$ & 0.110 & 0.091 & 0.040 & 0.087 & 0.218 & 0.065 & 1.000 & 0.077 & 0.185 & 0.088 & 0.178 & 0.073 & 0.143 & 0.070 & 1.000 & 0.046 \\
\hline$N R_{C}$ & 0.000 & 0.097 & 0.015 & 0.092 & 0.015 & 0.072 & 0.002 & 0.087 & 0.060 & 0.092 & 0.092 & 0.078 & 0.226 & 0.066 & 0.050 & 0.048 \\
\hline$A R_{C}$ & 0.110 & 0.094 & 0.108 & 0.081 & 0.058 & 0.068 & 0.013 & 0.084 & 0.172 & 0.091 & 0.092 & 0.080 & 0.017 & 0.080 & 0.004 & 0.050 \\
\hline$N A R_{C}$ & 0.248 & 0.088 & 0.056 & 0.083 & 0.058 & 0.068 & 0.054 & 0.082 & 0.172 & 0.091 & 0.178 & 0.073 & 0.134 & 0.071 & 0.050 & 0.048 \\
\hline \multicolumn{17}{|c|}{ Markov-switching weight } \\
\hline$N A_{M S}$ & 0.110 & 0.091 & 0.035 & 0.090 & 0.128 & 0.066 & 0.109 & 0.080 & 0.185 & 0.088 & 0.236 & 0.071 & 0.162 & 0.068 & 0.148 & 0.047 \\
\hline$N R_{M S}$ & 0.110 & 0.095 & 0.035 & 0.090 & 0.033 & 0.071 & 0.002 & 0.086 & 0.172 & 0.089 & 0.113 & 0.075 & 0.317 & 0.064 & 0.018 & 0.049 \\
\hline$A R_{M S}$ & 0.081 & 0.096 & 0.108 & 0.082 & 0.058 & 0.069 & 0.002 & 0.087 & 0.172 & 0.091 & 0.113 & 0.078 & 0.031 & 0.078 & 0.007 & 0.050 \\
\hline$N A R_{M S}$ & 1.000 & 0.087 & 0.108 & 0.081 & 0.219 & 0.064 & 0.464 & 0.077 & 1.000 & 0.084 & 1.000 & 0.068 & 0.314 & 0.065 & 0.361 & 0.046 \\
\hline
\end{tabular}

(a) Conventional Monetary policy period

\begin{tabular}{|c|c|c|c|c|c|c|c|c|c|c|c|c|c|c|c|c|}
\hline & \multicolumn{2}{|c|}{3 months } & \multicolumn{2}{|c|}{6 months } & \multicolumn{2}{|c|}{12 months } & \multicolumn{2}{|c|}{24 months } & \multicolumn{2}{|c|}{36 months } & \multicolumn{2}{|c|}{60 months } & \multicolumn{2}{|c|}{84 months } & \multicolumn{2}{|c|}{120 months } \\
\hline & $p_{M C S}$ & MSFE & $p_{M C S}$ & MSFE & $p_{M C S}$ & MSFE & $p_{M C S}$ & MSFE & $p_{M C S}$ & MSFE & $p_{M C S}$ & MSFE & $p_{M C S}$ & MSFE & $p_{M C S}$ & MSFE \\
\hline \multicolumn{17}{|c|}{ Single model } \\
\hline$N$ & 0.000 & 0.028 & 1.000 & 0.006 & 0.333 & 0.009 & 0.000 & 0.039 & 0.000 & 0.112 & 0.002 & 0.170 & 0.005 & 0.144 & 0.142 & 0.099 \\
\hline$A$ & 0.000 & 0.046 & 0.000 & 0.037 & 0.000 & 0.029 & 0.000 & 0.060 & 0.000 & 0.114 & 0.003 & 0.087 & 0.005 & 0.155 & 0.060 & 0.111 \\
\hline$R$ & 1.000 & 0.020 & 0.233 & 0.018 & 0.130 & 0.020 & 1.000 & 0.029 & 1.000 & 0.044 & 1.000 & 0.069 & 1.000 & 0.085 & 0.441 & 0.097 \\
\hline \multicolumn{17}{|c|}{ Equal weight } \\
\hline$N A_{E}$ & 0.000 & 0.066 & 000 & 0.048 & 0.000 & 0.039 & 0.000 & 0.069 & 0.000 & 0.139 & 0.002 & 0.156 & 0.005 & 0.165 & 0.060 & 0.111 \\
\hline$N R_{E}$ & 0.000 & 0.025 & .233 & 0.010 & 0.130 & 0.012 & 0.001 & 0.035 & 0.000 & 0.072 & 0.003 & 0.106 & 0.005 & 0.108 & 1.000 & 0.096 \\
\hline$A R_{E}$ & 0.000 & 0.041 & 000 & 0.035 & 0.000 & 0.033 & 0.000 & 0.054 & 0.000 & 0.083 & 0.020 & 0.079 & 0.005 & 0.124 & 0.060 & 0.109 \\
\hline$N A R_{E}$ & 0.000 & 0.100 & .000 & 0.081 & 0.000 & 0.072 & 0.000 & 0.102 & 0.000 & 0.145 & 0.002 & 0.147 & 0.005 & 0.183 & 0.006 & 0.143 \\
\hline \multicolumn{17}{|c|}{ Constant weight } \\
\hline$A_{C}$ & 0.000 & 0.047 & .000 & 0.022 & 0.130 & 0.019 & 0.000 & 0.052 & 0.000 & 0.110 & 0.002 & 0.120 & 0.005 & 0.140 & 0.091 & 0.102 \\
\hline$N R_{C}$ & 0.000 & 0.029 & 233 & 0.008 & 0.130 & 0.010 & 0.000 & 0.040 & 0.000 & 0.096 & 0.002 & 0.139 & 0.005 & 0.127 & 0.142 & 0.098 \\
\hline$A R_{C}$ & 0.000 & 0.061 & 0.000 & 0.053 & 0.000 & 0.046 & 0.000 & 0.074 & 0.000 & 0.119 & 0.003 & 0.097 & 0.005 & 0.160 & 0.006 & 0.125 \\
\hline$N A R_{C}$ & 0.000 & 0.101 & 0.000 & 0.071 & 0.000 & 0.065 & 0.000 & 0.106 & 0.000 & 0.171 & 0.002 & 0.193 & 0.005 & 0.206 & 0.006 & 0.148 \\
\hline \multicolumn{17}{|c|}{ Markov-switching weight } \\
\hline$N A_{M S}$ & 0.000 & 0.092 & 000 & 0.073 & 0.000 & 0.069 & 0.000 & 0.094 & 0.000 & 0.134 & 0.003 & 0.116 & 0.005 & 0.163 & 0.060 & 0.124 \\
\hline$N R_{M S}$ & 0.000 & 0.026 & .233 & 0.008 & 1.000 & 0.009 & 0.001 & 0.036 & 0.000 & 0.082 & 0.002 & 0.118 & 0.005 & 0.114 & 0.318 & 0.097 \\
\hline$A R_{M S}$ & 0.000 & 0.054 & 0.000 & 0.041 & 0.000 & 0.031 & 0.000 & 0.063 & 0.000 & 0.095 & 0.003 & 0.087 & 0.005 & 0.142 & 0.060 & 0.115 \\
\hline$N A R_{M S}$ & 0.000 & 0.157 & 0.000 & 0.135 & 0.000 & 0.128 & 0.000 & 0.160 & 0.000 & 0.213 & 0.001 & 0.218 & 0.002 & 0.254 & 0.001 & 0.193 \\
\hline
\end{tabular}

(b) Unconventional monetary policy period

Note: The MCS p-values and MSFEs are reported for maturities of 3, 6, 12, 24, 36, 60, 84, and 120 months in the period of unconventional monetary policy.

that show statistically similar forecasting performance to the best model. For example, when comparing the MSFEs of $A$ and $N A R_{M S}$ at 12-month-ahead forecasting horizon in the period of conventional monetary policy, we find that the two models perform similarly well although the best model selection procedure chooses $A$ for six of the eight different maturities while $N A R_{M S}$ is not chosen even for any maturity. For this reason, we consider an MCS for OOS forecast evaluations as a complementary model selection criterion. 
Table 5: Mean squared forecasting errors and MCS p-values for four-month-ahead forecasts

\begin{tabular}{|c|c|c|c|c|c|c|c|c|c|c|c|c|c|c|c|c|}
\hline & \multicolumn{2}{|c|}{3 months } & \multicolumn{2}{|c|}{6 months } & \multicolumn{2}{|c|}{12 months } & \multicolumn{2}{|c|}{24 months } & \multicolumn{2}{|c|}{36 months } & \multicolumn{2}{|c|}{60 months } & \multicolumn{2}{|c|}{84 months } & \multicolumn{2}{|c|}{120 months } \\
\hline & $p_{M C S}$ & MSFE & $p_{M C S}$ & MSFE & $p_{M C S}$ & MSFE & $p_{M C S}$ & MSFE & $p_{M C S}$ & MSFE & $p_{M C S}$ & MSFE & $p_{M C S}$ & MSFE & $p_{M C S}$ & MSFE \\
\hline \multicolumn{17}{|c|}{ Single model } \\
\hline$N$ & 0.001 & 0.632 & 0.013 & 0.584 & 0.003 & 0.517 & 0.003 & 0.524 & 0.006 & 0.486 & 0.001 & 0.329 & 0.190 & 0.253 & 0.095 & 0.172 \\
\hline$A$ & 0.080 & 0.575 & 0.013 & 0.519 & 0.005 & 0.464 & 0.025 & 0.486 & 0.067 & 0.470 & 0.584 & 0.284 & 0.000 & 0.296 & 0.022 & 0.187 \\
\hline$R$ & 0.001 & 0.639 & 0.000 & 0.628 & 0.000 & 0.579 & 0.003 & 0.538 & 0.006 & 0.513 & 0.001 & 0.329 & 0.430 & 0.250 & 0.095 & 0.178 \\
\hline \multicolumn{17}{|c|}{ Equal weight } \\
\hline$N A_{E}$ & 0.080 & 0.575 & 0.120 & 0.492 & 0.151 & 0.438 & 0.021 & 0.493 & 0.006 & 0.513 & 0.000 & 0.367 & 0.000 & 0.407 & 0.000 & 0.257 \\
\hline$N R_{E}$ & 0.000 & 0.640 & 0.000 & 0.613 & 0.000 & 0.558 & 0.000 & 0.543 & 0.006 & 0.500 & 0.000 & 0.331 & 0.190 & 0.254 & 0.022 & 0.179 \\
\hline$A R_{E}$ & 0.009 & 0.601 & 0.013 & 0.559 & 0.003 & 0.509 & 0.021 & 0.504 & 0.014 & 0.474 & 0.166 & 0.303 & 0.013 & 0.260 & 0.095 & 0.178 \\
\hline$N A R_{E}$ & 1.000 & 0.514 & 1.000 & 0.468 & 1.000 & 0.422 & 1.000 & 0.440 & 0.361 & 0.434 & 0.584 & 0.284 & 0.013 & 0.276 & 0.022 & 0.189 \\
\hline \multicolumn{17}{|c|}{ Constant weight } \\
\hline$N A_{C}$ & 0.009 & 0.578 & 0.065 & 0.514 & 0.091 & 0.449 & 0.093 & 0.459 & 0.181 & 0.438 & 0.262 & 0.288 & 0.544 & 0.240 & 1.000 & 0.157 \\
\hline$N R_{C}$ & 0.001 & 0.630 & 0.005 & 0.598 & 0.000 & 0.536 & 0.003 & 0.531 & 0.006 & 0.485 & 0.001 & 0.320 & 0.430 & 0.244 & 0.323 & 0.165 \\
\hline$A R_{C}$ & 0.009 & 0.601 & 0.013 & 0.538 & 0.003 & 0.486 & 0.021 & 0.503 & 0.014 & 0.483 & 0.262 & 0.298 & 0.000 & 0.301 & 0.004 & 0.195 \\
\hline$N A R_{C}$ & 0.080 & 0.560 & 0.020 & 0.515 & 0.006 & 0.460 & 0.049 & 0.465 & 0.115 & 0.440 & 0.262 & 0.289 & 1.000 & 0.236 & 0.391 & 0.157 \\
\hline \multicolumn{17}{|c|}{ Markov-switching weight } \\
\hline$N A_{M S}$ & 0.009 & 0.601 & 0.013 & 0.546 & 0.005 & 0.480 & 0.021 & 0.487 & 0.067 & 0.456 & 0.262 & 0.289 & 0.430 & 0.245 & 0.323 & 0.162 \\
\hline$N R_{M S}$ & 0.001 & 0.624 & 0.005 & 0.600 & 0.002 & 0.532 & 0.021 & 0.522 & 0.014 & 0.478 & 0.018 & 0.316 & 0.544 & 0.241 & 0.207 & 0.169 \\
\hline$A R_{M S}$ & 0.009 & 0.594 & 0.013 & 0.534 & 0.003 & 0.481 & 0.021 & 0.499 & 0.014 & 0.476 & 0.262 & 0.297 & 0.001 & 0.291 & 0.012 & 0.193 \\
\hline$N A R_{M S}$ & 0.080 & 0.546 & 0.065 & 0.502 & 0.025 & 0.450 & 0.194 & 0.456 & 1.000 & 0.433 & 1.000 & 0.279 & 0.544 & 0.238 & 0.323 & 0.161 \\
\hline
\end{tabular}

(a) Conventional monetary policy period

\begin{tabular}{|c|c|c|c|c|c|c|c|c|c|c|c|c|c|c|c|c|}
\hline & \multicolumn{2}{|c|}{3 months } & \multicolumn{2}{|c|}{6 months } & \multicolumn{2}{|c|}{12 months } & \multicolumn{2}{|c|}{24 months } & \multicolumn{2}{|c|}{36 months } & \multicolumn{2}{|c|}{60 months } & \multicolumn{2}{|c|}{84 months } & \multicolumn{2}{|c|}{120 months } \\
\hline & $p_{M C S}$ & MSFE & $p_{M C S}$ & MSFE & $p_{M C S}$ & MSFE & $p_{M C S}$ & MSFE & $p_{M C S}$ & MSFE & $p_{M C S}$ & MSFE & $p_{M C S}$ & MSFE & $p_{M C S}$ & MSFE \\
\hline \multicolumn{17}{|c|}{ Single model } \\
\hline$N$ & 0.000 & 0.183 & 0.103 & 0.141 & 0.040 & 0.151 & 0.000 & 0.258 & 0.000 & 0.431 & 0.019 & 0.589 & 0.056 & 0.540 & 0.276 & 0.428 \\
\hline$A$ & 0.000 & 0.389 & 0.000 & 0.428 & 0.000 & 0.417 & 0.000 & 0.502 & 0.000 & 0.628 & 0.073 & 0.473 & 0.010 & 0.696 & 0.087 & 0.543 \\
\hline$R$ & 1.000 & 0.109 & 1.000 & 0.129 & 1.000 & 0.139 & 1.000 & 0.155 & 1.000 & 0.215 & 1.000 & 0.334 & 1.000 & 0.376 & 1.000 & 0.392 \\
\hline \multicolumn{17}{|c|}{ Equal weight } \\
\hline$N A_{E}$ & 0.000 & 0.515 & 0.000 & 0.501 & 0.000 & 0.452 & 0.000 & 0.489 & 0.000 & 0.618 & 0.019 & 0.640 & 0.026 & 0.641 & 0.207 & 0.495 \\
\hline$N R_{E}$ & 0.000 & 0.161 & 0.021 & 0.151 & 0.000 & 0.164 & 0.000 & 0.229 & 0.000 & 0.332 & 0.073 & 0.460 & 0.106 & 0.456 & 0.553 & 0.401 \\
\hline$A R_{E}$ & 0.000 & 0.292 & 0.000 & 0.325 & 0.000 & 0.333 & 0.000 & 0.386 & 0.000 & 0.473 & 0.073 & 0.464 & 0.026 & 0.593 & 0.103 & 0.515 \\
\hline$N A R_{E}$ & 0.000 & 0.406 & 0.000 & 0.409 & 0.000 & 0.396 & 0.000 & 0.432 & 0.000 & 0.498 & 0.049 & 0.494 & 0.056 & 0.563 & 0.264 & 0.471 \\
\hline \multicolumn{17}{|c|}{ Constant weight } \\
\hline$N A_{C}$ & 0.000 & 0.319 & 0.000 & 0.282 & 0.000 & 0.260 & 0.000 & 0.324 & 0.000 & 0.439 & 0.073 & 0.466 & 0.106 & 0.500 & 0.553 & 0.402 \\
\hline$N R_{C}$ & 0.000 & 0.196 & 0.000 & 0.173 & 0.000 & 0.187 & 0.000 & 0.294 & 0.000 & 0.444 & 0.019 & 0.588 & 0.056 & 0.555 & 0.264 & 0.454 \\
\hline$A R_{C}$ & 0.000 & 0.455 & 0.000 & 0.499 & 0.000 & 0.500 & 0.000 & 0.579 & 0.000 & 0.692 & 0.034 & 0.586 & 0.009 & 0.777 & 0.057 & 0.635 \\
\hline$N A R_{C}$ & 0.000 & 0.338 & 0.000 & 0.312 & 0.000 & 0.304 & 0.000 & 0.375 & 0.000 & 0.485 & 0.034 & 0.537 & 0.056 & 0.558 & 0.264 & 0.455 \\
\hline \multicolumn{17}{|c|}{ Markov-switching weight } \\
\hline$N A_{M S}$ & 0.000 & 0.415 & 0.000 & 0.387 & 0.000 & 0.352 & 0.000 & 0.391 & 0.000 & 0.468 & 0.073 & 0.429 & 0.106 & 0.498 & 0.487 & 0.403 \\
\hline$N R_{M S}$ & 0.000 & 0.158 & 0.138 & 0.138 & 0.040 & 0.152 & 0.000 & 0.236 & 0.000 & 0.366 & 0.034 & 0.498 & 0.106 & 0.489 & 0.276 & 0.420 \\
\hline$A R_{M S}$ & 0.000 & 0.396 & 0.000 & 0.416 & 0.000 & 0.389 & 0.000 & 0.466 & 0.000 & 0.547 & 0.034 & 0.509 & 0.010 & 0.681 & 0.073 & 0.575 \\
\hline$N A R_{M S}$ & 0.000 & 0.381 & 0.000 & 0.368 & 0.000 & 0.354 & 0.000 & 0.406 & 0.000 & 0.500 & 0.034 & 0.519 & 0.036 & 0.571 & 0.207 & 0.473 \\
\hline
\end{tabular}

(b) Unconventional monetary policy period

Note: The MCS p-values and MSFEs are reported for maturities of 3, 6, 12, 24, 36, 60, 84, and 120 months.

Let $\mathcal{M}^{0}$ be a collection of combination models, including the individual models, and let the number of combinations of models be finite. The relative performance variables for combination models $i$ and $j$ are defined by

$$
d_{i j, t}(\tau, h)=L_{i, t}(\tau, h)-L_{j, t}(\tau, h), \text { for all } i, j \in \mathcal{M}^{0}
$$

and the expected loss is given by $\mu_{i j}(\tau, h)=\mathbb{E}\left[d_{i j, t}(\tau, h)\right]$. We rank the alternative combina- 
Table 6: Mean squared forecasting errors and MCS p-values for 12-month-ahead forecasts

\begin{tabular}{|c|c|c|c|c|c|c|c|c|c|c|c|c|c|c|c|c|}
\hline & \multicolumn{2}{|c|}{3 months } & \multicolumn{2}{|c|}{6 months } & \multicolumn{2}{|c|}{12 months } & \multicolumn{2}{|c|}{24 months } & \multicolumn{2}{|c|}{36 months } & \multicolumn{2}{|c|}{60 months } & \multicolumn{2}{|c|}{84 months } & \multicolumn{2}{|c|}{120 months } \\
\hline & $p_{M C S}$ & MSFE & $p_{M C S}$ & MSFE & $p_{M C S}$ & MSFE & $p_{M C S}$ & MSFE & $p_{M C S}$ & MSFE & $p_{M C S}$ & MSFE & $p_{M C S}$ & MSFE & $p_{M C S}$ & MSFE \\
\hline \multicolumn{17}{|c|}{ Single model } \\
\hline$N$ & 0.050 & 3.944 & 0.064 & 3.560 & 0.050 & 2.967 & 0.077 & 2.378 & 0.085 & 1.888 & 0.032 & 1.162 & 0.119 & 0.812 & 0.098 & 0.518 \\
\hline$A$ & 1.000 & 3.370 & 1.000 & 3.068 & 1.000 & 2.572 & 1.000 & 2.116 & 1.000 & 1.735 & 1.000 & 0.900 & 0.119 & 0.929 & 0.074 & 0.615 \\
\hline$R$ & 0.050 & 4.024 & 0.028 & 3.761 & 0.025 & 3.157 & 0.245 & 2.333 & 0.367 & 1.781 & 0.116 & 1.004 & 1.000 & 0.644 & 1.000 & 0.417 \\
\hline \multicolumn{17}{|c|}{ Equal weight } \\
\hline$N A_{E}$ & 0.318 & 3.423 & 0.495 & 3.093 & 0.413 & 2.609 & 0.245 & 2.229 & 0.078 & 1.908 & 0.032 & 1.255 & 0.030 & 1.163 & 0.015 & 0.777 \\
\hline$N R_{E}$ & 0.050 & 3.984 & 0.035 & 3.679 & 0.028 & 3.093 & 0.148 & 2.372 & 0.225 & 1.853 & 0.032 & 1.114 & 0.119 & 0.772 & 0.098 & 0.509 \\
\hline$A R_{E}$ & 0.092 & 3.686 & 0.128 & 3.399 & 0.117 & 2.865 & 0.245 & 2.235 & 0.367 & 1.767 & 0.116 & 0.993 & 0.119 & 0.803 & 0.098 & 0.531 \\
\hline$N A R_{E}$ & 0.375 & 3.421 & 0.212 & 3.164 & 0.134 & 2.693 & 0.283 & 2.169 & 0.379 & 1.748 & 0.057 & 1.037 & 0.119 & 0.847 & 0.085 & 0.567 \\
\hline \multicolumn{17}{|c|}{ Constant weight } \\
\hline$N A_{C}$ & 0.092 & 3.734 & 0.128 & 3.346 & 0.117 & 2.774 & 0.259 & 2.210 & 0.379 & 1.759 & 0.032 & 1.057 & 0.119 & 0.781 & 0.098 & 0.506 \\
\hline$N R_{C}$ & 0.050 & 3.904 & 0.064 & 3.583 & 0.050 & 3.006 & 0.127 & 2.372 & 0.152 & 1.876 & 0.032 & 1.154 & 0.119 & 0.809 & 0.098 & 0.529 \\
\hline$A R_{C}$ & 0.092 & 3.498 & 0.128 & 3.195 & 0.117 & 2.713 & 0.245 & 2.222 & 0.279 & 1.814 & 0.057 & 1.019 & 0.090 & 0.960 & 0.051 & 0.647 \\
\hline$N A R_{C}$ & 0.092 & 3.621 & 0.128 & 3.298 & 0.117 & 2.783 & 0.245 & 2.230 & 0.282 & 1.785 & 0.032 & 1.087 & 0.119 & 0.799 & 0.098 & 0.520 \\
\hline \multicolumn{17}{|c|}{ Markov-switching weight } \\
\hline$N A_{M S}$ & 0.092 & 3.793 & 0.128 & 3.440 & 0.117 & 2.868 & 0.245 & 2.287 & 0.279 & 1.812 & 0.032 & 1.048 & 0.119 & 0.808 & 0.098 & 0.527 \\
\hline$N R_{M S}$ & 0.092 & 3.836 & 0.128 & 3.526 & 0.117 & 2.965 & 0.245 & 2.328 & 0.279 & 1.835 & 0.032 & 1.116 & 0.119 & 0.773 & 0.098 & 0.506 \\
\hline$A R_{M S}$ & 0.092 & 3.603 & 0.128 & 3.280 & 0.117 & 2.733 & 0.259 & 2.200 & 0.367 & 1.774 & 0.116 & 0.984 & 0.119 & 0.906 & 0.057 & 0.615 \\
\hline$N A R_{M S}$ & 0.166 & 3.464 & 0.149 & 3.175 & 0.134 & 2.709 & 0.283 & 2.191 & 0.379 & 1.752 & 0.032 & 1.043 & 0.119 & 0.789 & 0.098 & 0.510 \\
\hline
\end{tabular}

(a) Conventional monetary policy period

\begin{tabular}{|c|c|c|c|c|c|c|c|c|c|c|c|c|c|c|c|c|}
\hline & \multicolumn{2}{|c|}{3 months } & \multicolumn{2}{|c|}{6 months } & \multicolumn{2}{|c|}{12 months } & \multicolumn{2}{|c|}{24 months } & \multicolumn{2}{|c|}{36 months } & \multicolumn{2}{|c|}{60 months } & \multicolumn{2}{|c|}{84 months } & \multicolumn{2}{|c|}{120 months } \\
\hline & $p_{M C S}$ & MSFE & $p_{M C S}$ & MSFE & $p_{M C S}$ & MSFE & $p_{M C S}$ & MSFE & $p_{M C S}$ & MSFE & $p_{M C S}$ & MSFE & $p_{M C S}$ & MSFE & $p_{M C S}$ & MSFE \\
\hline \multicolumn{17}{|c|}{ Single model } \\
\hline$N$ & 0.000 & 0.442 & 0.000 & 0.428 & 0.000 & 0.492 & 0.000 & 0.687 & 0.000 & 0.969 & 0.000 & 1.168 & 0.020 & 1.068 & 0.058 & 0.883 \\
\hline$A$ & 0.000 & 1.354 & 0.000 & 1.551 & 0.000 & 1.616 & 0.000 & 1.753 & 0.000 & 1.925 & 0.000 & 1.405 & 0.000 & 1.727 & 0.003 & 1.347 \\
\hline$R$ & 1.000 & 0.099 & 1.000 & 0.169 & 1.000 & 0.187 & 1.000 & 0.168 & 1.000 & 0.236 & 1.000 & 0.490 & 1.000 & 0.662 & 1.000 & 0.686 \\
\hline \multicolumn{17}{|c|}{ Equal weight } \\
\hline$N A_{E}$ & 0.000 & 1.390 & 0.000 & 1.440 & 0.000 & 1.364 & 0.000 & 1.307 & 0.000 & 1.421 & 0.000 & 1.289 & 0.005 & 1.246 & 0.038 & 1.009 \\
\hline$N R_{E}$ & 0.000 & 0.297 & 0.000 & 0.341 & 0.000 & 0.399 & 0.000 & 0.482 & 0.000 & 0.625 & 0.001 & 0.790 & 0.092 & 0.806 & 0.314 & 0.716 \\
\hline$A R_{E}$ & 0.000 & 0.651 & 0.000 & 0.786 & 0.000 & 0.854 & 0.000 & 0.902 & 0.000 & 0.991 & 0.001 & 0.869 & 0.020 & 1.047 & 0.051 & 0.887 \\
\hline$N A R_{E}$ & 0.000 & 0.850 & 0.000 & 0.939 & 0.000 & 0.962 & 0.000 & 0.938 & 0.000 & 0.954 & 0.001 & 0.796 & 0.048 & 0.867 & 0.304 & 0.723 \\
\hline \multicolumn{17}{|c|}{ Constant weight } \\
\hline$N A_{C}$ & 0.000 & 0.940 & 0.000 & 0.934 & 0.000 & 0.904 & 0.000 & 0.930 & 0.000 & 1.053 & 0.001 & 0.982 & 0.021 & 0.996 & 0.086 & 0.833 \\
\hline$N R_{C}$ & 0.000 & 0.422 & 0.000 & 0.453 & 0.000 & 0.543 & 0.000 & 0.720 & 0.000 & 0.946 & 0.000 & 1.112 & 0.020 & 1.035 & 0.058 & 0.858 \\
\hline$A R_{C}$ & 0.000 & 1.185 & 0.000 & 1.373 & 0.000 & 1.454 & 0.000 & 1.565 & 0.000 & 1.688 & 0.000 & 1.280 & 0.000 & 1.519 & 0.004 & 1.209 \\
\hline$N A R_{C}$ & 0.000 & 0.858 & 0.000 & 0.878 & 0.000 & 0.893 & 0.000 & 0.926 & 0.000 & 1.022 & 0.001 & 0.973 & 0.030 & 0.962 & 0.170 & 0.791 \\
\hline \multicolumn{17}{|c|}{ Markov-switching weight } \\
\hline$N A_{M S}$ & 0.000 & 1.051 & 0.000 & 1.065 & 0.000 & 1.023 & 0.000 & 1.008 & 0.000 & 1.080 & 0.001 & 0.905 & 0.030 & 0.966 & 0.117 & 0.807 \\
\hline$N R_{M S}$ & 0.000 & 0.319 & 0.000 & 0.341 & 0.000 & 0.422 & 0.000 & 0.580 & 0.000 & 0.794 & 0.001 & 0.981 & 0.030 & 0.950 & 0.117 & 0.807 \\
\hline$A R_{M S}$ & 0.000 & 1.019 & 0.000 & 1.131 & 0.000 & 1.117 & 0.000 & 1.179 & 0.000 & 1.231 & 0.001 & 0.975 & 0.002 & 1.256 & 0.016 & 1.042 \\
\hline$N A R_{M S}$ & 0.000 & 0.908 & 0.000 & 0.949 & 0.000 & 0.956 & 0.000 & 0.962 & 0.000 & 1.033 & 0.001 & 0.950 & 0.021 & 0.975 & 0.092 & 0.813 \\
\hline
\end{tabular}

(b) Unconventional monetary policy period

Note: The MCS p-values and MSFEs are reported for maturities of 3, 6, 12, 24, 36, 60, 84, and 120 months. The last column shows the frequency of being included in the MCSs across different maturities for each model combination.

tion models in terms of the expected loss, such that for a pair $(\tau, h)$, the combination model $i$ is preferred to alternative $j$ if $\mu_{i j}(\tau, h)<0$.

The MCS at level $\alpha$ is defined as follows: for each pair of $\tau$ and $h$,

$$
\mathcal{M}_{1-\alpha}^{*}(\tau, h)=\left\{i \in \mathcal{M}^{0}: \mu_{i j}(\tau, h) \leq 0 \text { for all } j \in \mathcal{M}^{0}\right\}
$$


where the MCS procedure conducts a sequence of significance tests at level $\alpha$. The combination models that are found to be significantly inferior to other combination models of $\mathcal{M}^{0}$ are eliminated. Therefore, the hypotheses for the tests take the form

$$
H_{0, \mathcal{M}}: \mu_{i j}=0 \text { for all } i, j \in \mathcal{M}
$$

where $\mathcal{M} \subset \mathcal{M}^{0}{ }^{11}$ Thus, the MCS at level $\alpha, \mathcal{M}_{1-\alpha}^{*}(\tau, h)$, for a pair $(\tau, h)$ consists of the combination models that survive all tests at level $\alpha$. We compute the MCS $p$-values for the tests using $B=10,000$ bootstraps with a block size of $k=12 .^{12}$

Table 7 reports the frequency of inclusion in $90 \%$ model confidence sets for each model combination across different maturities at each forecasting horizon. The models with pvalues greater than or equal to 0.10 are included in the MCSs. Tables $4-6$ present the MCS p-values across all the mixtures for each maturity at one-, four-, and 12-month-ahead forecast horizons, respectively. ${ }^{13}$

At the one-month-ahead forecasting horizon during the conventional monetary policy period, $N A R_{M S}$ is included for all maturities, and $N A_{C}$ and $N A_{M S}$ are included for seven of the maturities. Furthermore, $R$ is included for all maturities during the unconventional monetary policy period, but the other mixture models are only included for three different maturities or less. At the four-month-ahead horizon, $N A R_{E}$ is included for six different maturities during the conventional monetary policy period, whereas $R$ is included for all maturities during the unconventional monetary policy period. Finally, at the 12-month-ahead horizon during the conventional monetary policy period, $A$ is included for seven different maturities and $A R_{E}, N A R_{E}, A R_{M S}$, and $N A R_{M S}$ are included for six different maturities. Here, $R$ is included for all maturities during the unconventional monetary policy period.

For the overall forecasting evaluation period at one-, four-, and 12-month-ahead forecasting horizons, we find that the RW model outperforms the other mixture models for all maturities. The performance of the RW model is likely to originate from its superiority during the unconventional monetary policy period. This discrepancy in the forecasting results

\footnotetext{
${ }^{11}$ We use the range-based procedure because Hansen, Lunde and Nason (2014) find that the range-based procedure has better power properties and produces smaller model confidence sets with proper coverage probabilities than the maximum $t$-statistic. See Hansen, Lunde and Nason (2014) for a detailed discussion.

${ }^{12}$ We use an R package MCS developed by Bernardi and Catania (2018). We thank them for sharing their code.

${ }^{13}$ See the online appendix for the full sample forecasting results.
} 
Table 7: MCS Results during the Periods of Conventional and Unconventional Monetary Policy

\begin{tabular}{|c|c|c|c|c|c|c|c|c|c|}
\hline & \multicolumn{9}{|c|}{ Frequency of inclusion in the $90 \%$ MCSs } \\
\hline & \multicolumn{3}{|c|}{ 1-month-ahead } & \multicolumn{3}{|c|}{ 4-month-ahead } & \multicolumn{3}{|c|}{ 12-month-ahead } \\
\hline & Con. & Uncon. & All & Con. & Uncon. & All & Con. & Uncon. & All \\
\hline \multicolumn{10}{|c|}{ Single model } \\
\hline$N$ & 1 & 3 & 3 & 1 & 2 & 3 & 1 & 0 & 3 \\
\hline$A$ & 4 & 0 & 1 & 1 & 0 & 1 & 7 & 0 & 1 \\
\hline$R$ & 4 & 8 & 8 & 1 & 8 & 8 & 5 & 8 & 8 \\
\hline \multicolumn{10}{|c|}{ Equal weight } \\
\hline$N A_{E}$ & 3 & 0 & 0 & 2 & 1 & 0 & 4 & 0 & 3 \\
\hline$N R_{E}$ & 3 & 3 & 3 & 1 & 2 & 3 & 3 & 1 & 3 \\
\hline$A R_{E}$ & 5 & 0 & 0 & 1 & 1 & 1 & 6 & 0 & 3 \\
\hline $\begin{array}{l}N A R_{E} \\
\text { Constan }\end{array}$ & $\begin{array}{c}4 \\
\text { weigh }\end{array}$ & 0 & 0 & 6 & 1 & 1 & 6 & 1 & 3 \\
\hline$N A_{C}$ & 7 & 1 & 3 & 4 & 2 & 5 & 5 & 0 & 3 \\
\hline$N R_{C}$ & 1 & 3 & 3 & 2 & 1 & 2 & 3 & 0 & 3 \\
\hline$A R_{C}$ & 3 & 0 & 0 & 1 & 0 & 0 & 4 & 0 & 2 \\
\hline$N A R_{C}$ & 4 & 0 & 0 & 4 & 1 & 2 & 5 & 1 & 3 \\
\hline \multicolumn{10}{|c|}{ Markov-switching weight } \\
\hline$N A_{M S}$ & 7 & 0 & 0 & 3 & 2 & 2 & 5 & 1 & 1 \\
\hline$N R_{M S}$ & 4 & 3 & 3 & 2 & 3 & 3 & 5 & 1 & 3 \\
\hline$A R_{M S}$ & 3 & 0 & 0 & 1 & 0 & 0 & 6 & 0 & 2 \\
\hline$N A R_{M S}$ & 8 & 0 & 0 & 5 & 1 & 1 & 6 & 0 & 3 \\
\hline
\end{tabular}

Note: We present the frequency of inclusion in the MCSs across eight different maturities for each model combination given a forecasting horizon. We calculate these frequencies for three different forecasting evaluation periods: conventional monetary policy period only ('Con.'); unconventional monetary policy period only ('Uncon.'); and both conventional and unconventional monetary policy periods ('All'). For example, the number 8 for the model ' $\mathrm{R}$ ' in the column of 'All' under 'one-month-ahead' means that the RW model is included in the MCSs for all the eight different maturities at one-month-ahead forecasting horizon when evaluating the forecasting performance of the competing models over both conventional and unconventional monetary policy periods.

of the mixture models before and after the crisis is consistent with those for the best model selection based on the MSFEs, as reported in Section 3.2.

In short, we find similar patterns in the best model selection and MCS procedures for all forecasting horizons and maturities. That is, the mixtures of DNS, AFNS, and RW models perform well, and those mixture models always include the AFNS in the MCSs during the conventional monetary policy period. These results demonstrate that no-arbitrage restrictions in the AFNS are useful in improving the forecasting performance of the mixture 
models during the conventional monetary policy period. However, this is not the case during the unconventional monetary policy period and the RW model dominates the other models for all maturities.

\section{Understanding the Yield Curve during the Uncon- ventional Monetary Policy Period}

In this section, we argue that the different channels and effects of conventional and unconventional monetary policies on the term structure of interest rates explain why the AFNS (i.e., no-arbitrage restrictions) plays an important role in forecasting the yield curve during the period of conventional policy, but not during the period of unconventional policy. We briefly explain our intuitions about the relationship below and provide empirical evidence for them.

During periods of conventional policy, the Fed uses a short-term policy rate as a monetary policy instrument (i.e., the federal funds rate) that affects long-term bond yields through market expectations. This implies that conventional monetary policy leads to high correlations between short- and long-term bond yields and considerable variation in yields across all maturities. Under these circumstances, the cross-equation restrictions such as the noarbitrage condition should be useful in improving a yield curve model's forecasting ability. Thus, the AFNS model can play an important role in improving forecasting ability in mixture models in periods of conventional monetary policy. Many studies in the literature (e.g., Ang and Piazzesi (2003), Almeida and Vicente (2008), Moench (2008), Carriero and Giacomini (2011), and Christensen, Diebold and Rudebusch (2011)) report the similar finding that imposing no-arbitrage restrictions on a broader class of yield curve models improve their forecasting abilities using data sets from before the global financial crisis.

Since the crisis, however, the U.S. economy had shown a drastic reduction in interest rates, with the federal funds rates at nearly zero. To stimulate household and business spending and support economy recovery, the Fed made a series of large-scale asset purchases, known as 'Quantitative Easing', between December 2008 and October 2014. During this period of unconventional monetary policy, the Fed purchased long-term Treasuries and other longterm bonds, which put downward pressure on the yields of a wide range of longer-term 
securities, while short-term yields were constrained by the zero lower bound. In addition, in September 2011, the Fed announced a maturity extension program, the so called "Operation Twist" which involved the purchase of longer-term Treasury securities through the sale of an equivalent amount of shorter-term securities. As a result, it increased short-term bond yields, but lowered long-term bond yields without altering the total size of the Fed's balance sheet. Thus, unconventional monetary policy can directly change long-term bond yields, resulting in low correlations between short- and long-term bond yields. The short-term rate was constrained at zero, which meant there was little variation in short-term bond yields.

To illustrate these points, we calculate correlations across different maturities and standard deviations of changes in yields and then relate the changes to monetary policy regimes. We also examine the forecasting performance of key models over time in detail.

\subsection{Correlations and Changes in Yields over Conventional and Unconventional Monetary Policy Periods}

Table 8 calculates the sample correlations across maturities for the two subsamples we used for the forecasting evaluation. The correlations between short- and long-term bond yields significantly decreased during the unconventional monetary policy period (2009-2013) compared to the conventional policy period (2004-2008), while correlations between long-term bond yields remained very high. For example, the correlations between long-term yields are very close to one for both subsamples, but the correlations between 3-month yield and 120 -month yield decreases from 0.74 to 0.40 across the two subsamples.

Table 9 presents the model-implied correlations for the DNS and AFNS models. Here, we estimate the models for the full sample (i.e., February 1994-December 2013) and simulate the yield curve data at the parameter estimates. Note that the AFNS generates high correlations, ranging from 0.80 to 0.99 , which are similar to the sample correlations in the first subsample period. Meanwhile, the correlations from the DNS ranges from 0.32 to 0.98. Given that the DNS produces relatively lower correlations, especially between short- and long-term bond yields, no-arbitrage restrictions in the AFNS appear to be more closely associated with the high correlations between short- and long-term bond yields. In both models,

only a three factors are responsible for explaining the dynamics of the entire yield curve so that high correlations across different maturities are expected. But we find much lower 
Table 8: Correlations across Maturities for the Two Subsamples

\begin{tabular}{rccccccc}
\hline & $3 \mathrm{~m}$ & $6 \mathrm{~m}$ & $12 \mathrm{~m}$ & $24 \mathrm{~m}$ & $36 \mathrm{~m}$ & $60 \mathrm{~m}$ & $84 \mathrm{~m}$ \\
\hline $6 \mathrm{~m}$ & 1.00 & & & & & & \\
$12 \mathrm{~m}$ & 0.99 & 1.00 & & & & & \\
$24 \mathrm{~m}$ & 0.97 & 0.98 & 0.99 & & & & \\
$36 \mathrm{~m}$ & 0.95 & 0.96 & 0.97 & 1.00 & & & \\
$60 \mathrm{~m}$ & 0.91 & 0.92 & 0.93 & 0.97 & 0.99 & & \\
$84 \mathrm{~m}$ & 0.85 & 0.85 & 0.88 & 0.92 & 0.95 & 0.99 & \\
$120 \mathrm{~m}$ & 0.74 & 0.75 & 0.78 & 0.83 & 0.87 & 0.94 & 0.98 \\
\hline
\end{tabular}

(a) January 2004-December 2008 (conventional monetary policy)

\begin{tabular}{rccccccc}
\hline & $3 \mathrm{~m}$ & $6 \mathrm{~m}$ & $12 \mathrm{~m}$ & $24 \mathrm{~m}$ & $36 \mathrm{~m}$ & $60 \mathrm{~m}$ & $84 \mathrm{~m}$ \\
\hline $6 \mathrm{~m}$ & 0.91 & & & & & & \\
$12 \mathrm{~m}$ & 0.80 & 0.94 & & & & & \\
$24 \mathrm{~m}$ & 0.63 & 0.75 & 0.91 & & & & \\
$36 \mathrm{~m}$ & 0.56 & 0.67 & 0.84 & 0.99 & & & \\
$60 \mathrm{~m}$ & 0.45 & 0.54 & 0.72 & 0.92 & 0.97 & & \\
$84 \mathrm{~m}$ & 0.42 & 0.51 & 0.69 & 0.89 & 0.95 & 0.99 & \\
$120 \mathrm{~m}$ & 0.40 & 0.46 & 0.63 & 0.85 & 0.92 & 0.98 & 0.99 \\
\hline \multicolumn{7}{l}{ (b) January } & $2009-$ December 2013 (unconventional monetary policy)
\end{tabular}

Note: We calculate the sample correlations across maturities for two subsamples: Jan. 2004-Dec. 2008 and Jan. 2009-Dec. 2013. These subsamples are used to examine the effects of conventional and unconventional monetary policy on forecasting the yield curves in Sections 3.2 and 3.3.

correlations between short- and long-term bond yields in the DNS compared to the AFNS, mainly because the factor loadings and factor dynamics in the AFNS are more tightly constrained by no-arbitrage restrictions. The high correlations in the AFNS model align with the high correlations observed in the data during the conventional monetary policy period, which is consistent with the positive effect of the no-arbitrage condition on forecast accuracy in that period.

We also measure the variation in the bond yields over time. Here, small variations indicate that the RW model is preferred, because this model implies there is no difference between the forecasts and the current yields. Table 10 reports the standard deviations of the changes in the yields for the same subsamples using $S D\left(\Delta y_{t+h, t}^{O}(\tau)\right)$ for $h=1,4,12$, where $\Delta y_{t+h, t}^{O}(\tau)=y_{t+h}^{O}(\tau)-y_{t}^{O}(\tau)$. The standard deviation of 12-month-ahead changes in yields with 120 months to maturity is much smaller than that of three-month yields during the conventional monetary policy period because short-term interest rates are more sensitive 
Table 9: Model-implied bond yield correlations

\begin{tabular}{rccccccc}
\hline & $3 \mathrm{~m}$ & $6 \mathrm{~m}$ & $12 \mathrm{~m}$ & $24 \mathrm{~m}$ & $36 \mathrm{~m}$ & $60 \mathrm{~m}$ & $84 \mathrm{~m}$ \\
\hline $6 \mathrm{~m}$ & 0.89 & & & & & & \\
$12 \mathrm{~m}$ & 0.68 & 0.81 & & & & & \\
$24 \mathrm{~m}$ & 0.55 & 0.77 & 0.88 & & & & \\
$36 \mathrm{~m}$ & 0.47 & 0.70 & 0.84 & 0.98 & & & \\
$60 \mathrm{~m}$ & 0.39 & 0.62 & 0.77 & 0.93 & 0.94 & & \\
$84 \mathrm{~m}$ & 0.35 & 0.58 & 0.74 & 0.90 & 0.92 & 0.94 & \\
$120 \mathrm{~m}$ & 0.32 & 0.53 & 0.69 & 0.86 & 0.89 & 0.94 & 0.98 \\
\hline
\end{tabular}

(a) DNS

\begin{tabular}{rccccccc}
\hline & $3 \mathrm{~m}$ & $6 \mathrm{~m}$ & $12 \mathrm{~m}$ & $24 \mathrm{~m}$ & $36 \mathrm{~m}$ & $60 \mathrm{~m}$ & $84 \mathrm{~m}$ \\
\hline $6 \mathrm{~m}$ & 0.93 & & & & & & \\
$12 \mathrm{~m}$ & 0.87 & 0.88 & & & & & \\
$24 \mathrm{~m}$ & 0.89 & 0.92 & 0.94 & & & & \\
$36 \mathrm{~m}$ & 0.88 & 0.90 & 0.92 & 0.99 & & & \\
$60 \mathrm{~m}$ & 0.85 & 0.86 & 0.88 & 0.95 & 0.96 & & \\
$84 \mathrm{~m}$ & 0.81 & 0.82 & 0.83 & 0.91 & 0.92 & 0.93 & \\
$120 \mathrm{~m}$ & 0.81 & 0.80 & 0.80 & 0.88 & 0.91 & 0.93 & 0.95 \\
\hline
\end{tabular}

(b) AFNS

Note: We calculate the model-implied correlation using the simulated yield data from the DNS and AFNS models.

Table 10: Standard deviations of yield changes

\begin{tabular}{rrrrrrrrr}
\hline & $3 \mathrm{~m}$ & $6 \mathrm{~m}$ & $12 \mathrm{~m}$ & $24 \mathrm{~m}$ & $36 \mathrm{~m}$ & $60 \mathrm{~m}$ & $84 \mathrm{~m}$ & $120 \mathrm{~m}$ \\
\hline 1-month-ahead & 0.33 & 0.30 & 0.29 & 0.30 & 0.31 & 0.29 & 0.28 & 0.27 \\
4-month-ahead & 0.82 & 0.81 & 0.79 & 0.77 & 0.74 & 0.62 & 0.55 & 0.48 \\
12-month-ahead & 1.88 & 1.83 & 1.68 & 1.45 & 1.28 & 0.96 & 0.80 & 0.64 \\
\hline
\end{tabular}

(a) January 2004-December 2008 (conventional monetary policy)

\begin{tabular}{rrrrrrrrr}
\hline & $3 \mathrm{~m}$ & $6 \mathrm{~m}$ & $12 \mathrm{~m}$ & $24 \mathrm{~m}$ & $36 \mathrm{~m}$ & $60 \mathrm{~m}$ & $84 \mathrm{~m}$ & $120 \mathrm{~m}$ \\
\hline 1-month-ahead & 0.04 & 0.04 & 0.06 & 0.12 & 0.17 & 0.24 & 0.26 & 0.26 \\
4-month-ahead & 0.11 & 0.18 & 0.19 & 0.24 & 0.34 & 0.52 & 0.57 & 0.57 \\
12-month-ahead & 0.53 & 0.55 & 0.54 & 0.46 & 0.47 & 0.66 & 0.75 & 0.77 \\
\hline
\end{tabular}

(b) January 2009-December 2013 (unconventional monetary policy)

Note: We calculate the standard deviations of the changes in the yields $S D\left(\Delta y_{t+h, t}^{O}(\tau)\right)$ for $h=1,4,12$, where $\Delta y_{t+h, t}^{O}(\tau)=y_{t+h}^{O}(\tau)-y_{t}^{O}(\tau)$ for two subsamples: January 2004-December 2008 and January 2009December 2013. These are used for the subsample analysis of the forecasting evaluations in Sections 3.2 and 3.3. 
to the policy rate. This implies that the RW model would be more useful in predicting long-term yields at long forecasting horizons than it would in predicting short-term yields at short forecasting horizons. This conjecture is confirmed by Table 3 panel (b), which shows that the RW model is chosen as the best model when forecasting yields with 84 and 120 months to maturity at longer forecasting horizons.

In addition, we find that the variation in the yields with 36 months or less to maturity has decreased significantly since 2009, whereas the variation in the yields with 60 months or longer to maturity has not changed considerably. For example, the standard deviation of the one-month changes in the yields with three months to maturity $\left(S D\left(\Delta y_{t+1, t}^{O}(\tau=3 m)\right)\right.$ decreased from 0.33 to 0.04 , while that of the one-month changes in the yields with 120 months to maturity remained stable, changing from 0.27 to 0.26 . As a result, the RW model tends to perform well in terms of predicting yields with 36 months or less to maturity during the second subsample period.

\subsection{Forecasting Performance over Time: Cumulative Squared Fore- casting Errors}

To examine the relative importance of models at each point in time in detail, we plot the cumulative squared forecasting errors of the RW model (benchmark) minus the cumulative squared forecasting errors of the AFNS model over time for three-month, 36-month, and 120month yields in Figure 1. ${ }^{14}$ The cumulative squared forecasting error at time $t$ for yields with $\tau$ months to maturity at the forecasting horizon $h$ is given by $\sum_{s=1}^{t}\left[L_{R, s}(\tau, h)-L_{A, s}(\tau, h)\right]$. Whenever a line increases, the AFNS model forecasts better; whenever it decreases, the RW forecasts better. We choose the AFNS model for the comparison to verify the role of no-arbitrage restrictions in forecasting the yield curves. Plotting the cumulative squared forecasting errors is a useful graphical device to help identify periods in which no-arbitrage restrictions are useful in forecasting the yield curve relative to the RW benchmark and to determine whether these periods are consistent with those under conventional monetary policy. $^{15}$

We find that the differences for three-month and 36-month yields show an upward drift

\footnotetext{
${ }^{14}$ We find similar patterns for yields to other maturities. The complete figures are available upon request.

15 Note that a starting date for this analysis does not alter this pattern because it will only shift the graph up or down so that the results are robust to the choice of forecasting evaluation sample.
} 
Figure 1: AFNS vs. RW: Difference in cumulative mean squared forecasting errors
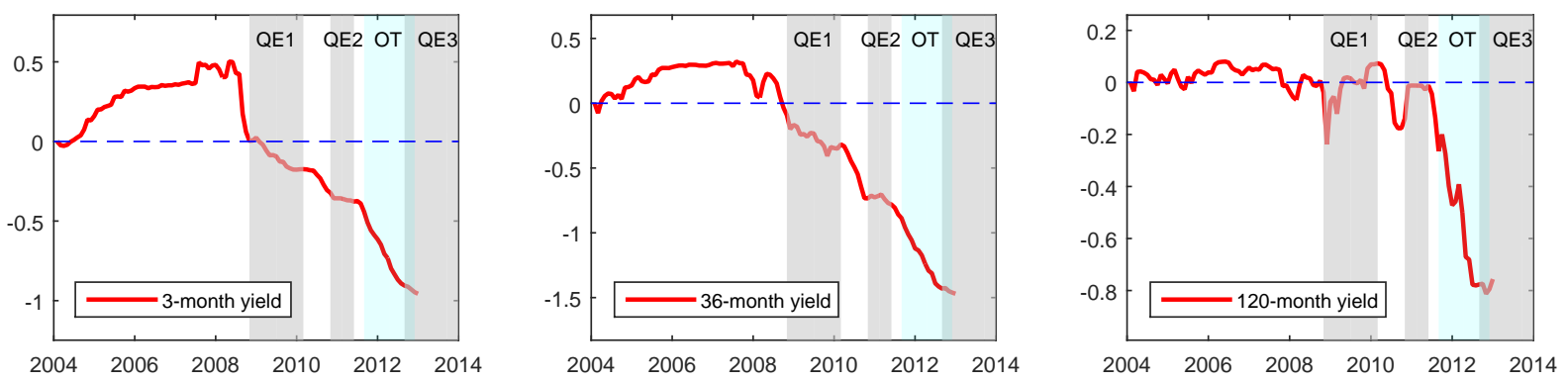

(a) 1-month-ahead forecasts
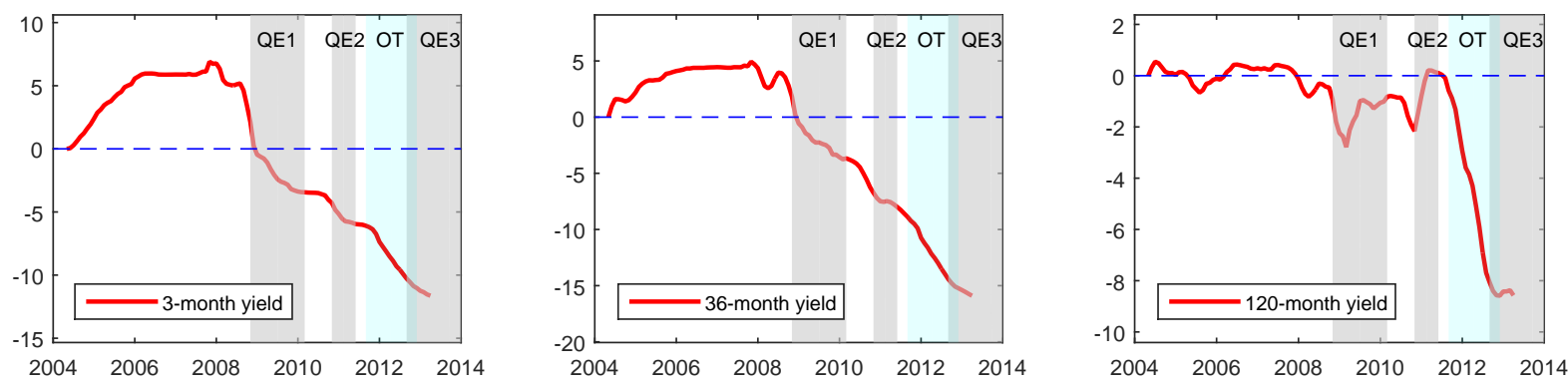

(b) 4-month-ahead forecasts
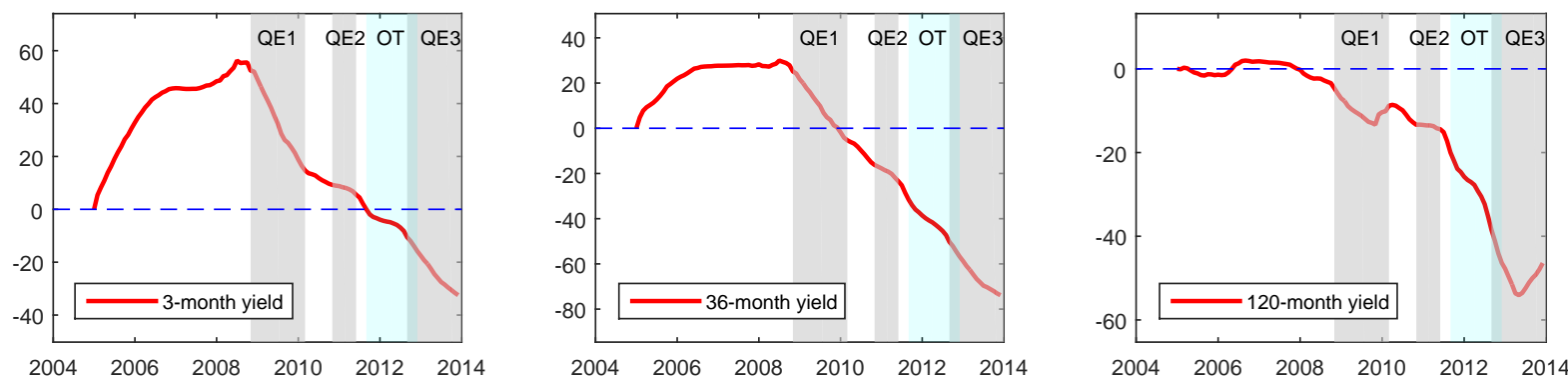

(c) 12-month-ahead forecasts

Note: We plot the cumulative mean squared forecasting errors of the random walk model $(R)$ minus the cumulative mean squared forecasting errors of the arbitrage-free Neslon-Siegel Model $(A)$ :

$\sum_{s=1}^{t}\left[L_{R, s}(\tau, h)-L_{A, s}(\tau, h)\right]$. The x-axis indicates time $t+h$. Whenever a line increases, the

arbitrage-free Nelson-Siegel model forecasts better; whenever it decreases, the random walk model forecasts better. The grey shaded areas correspond to three quantitative easing programs QE1, QE2, and QE3; and the blue shaded area corresponds to the maturity extension program. There is overlap between the maturity extension program and QE3 from September 2012 to December 2012.

(i.e., the AFNS performs better) during the conventional monetary policy period, while they exhibit a downward drift since QE1 started. For the 120-month yield, two models perform similarly during the conventional monetary policy period, but the downward drift is more 
Figure 2: $N A R_{M S}$ vs. RW: Difference in cumulative mean squared forecasting errors
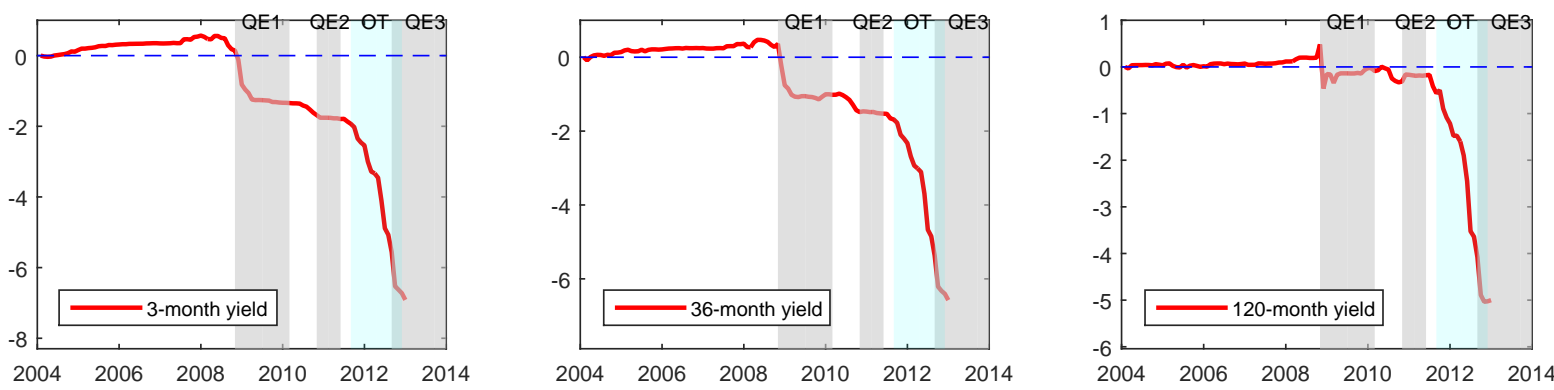

(a) 1-month-ahead forecasts
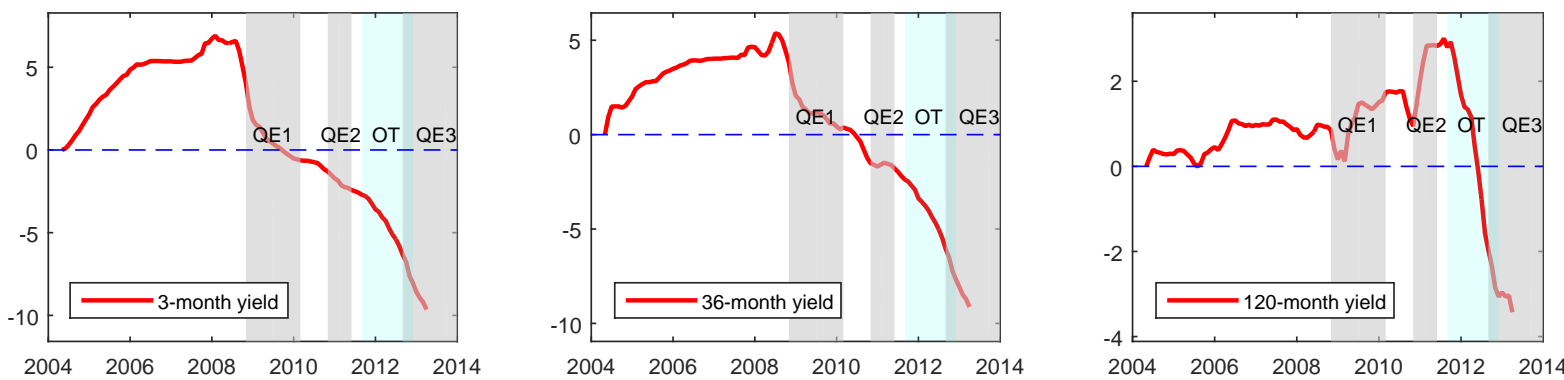

(b) 4-month-ahead forecasts
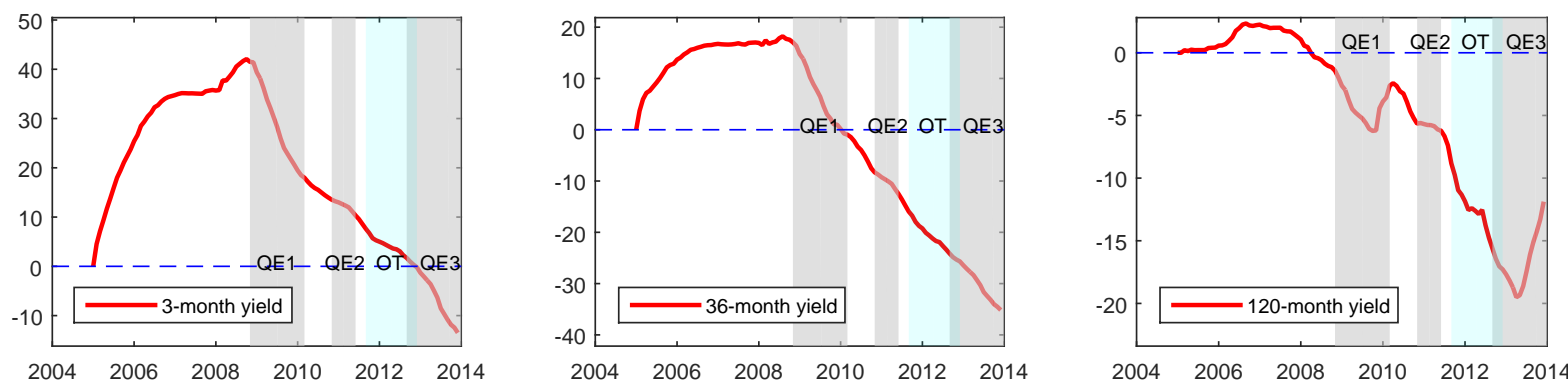

(c) 12-month-ahead forecasts

Note: We plot the cumulative mean squared forecasting errors of the random walk model $(R)$ minus the cumulative mean squared forecasting errors of the Markov-switching mixture of three models $\left(N A R_{M S}\right)$ : $\sum_{s=1}^{t}\left[L_{R, s}(\tau, h)-L_{N A R_{M S}, s}(\tau, h)\right]$. The x-axis indicates time $t+h$. Whenever a line increases, $N A R_{M S}$ forecasts better; whenever it decreases, $R$ forecasts better. The grey shaded areas correspond to three quantitative easing programs QE1, QE2, and QE3; and the blue shaded area corresponds to the maturity extension program. There is overlap between the maturity extension program and QE3 from September 2012 to December 2012.

pronounced during the Operation Twist period in 2011-2012. ${ }^{16}$ As we discussed in the

\footnotetext{
${ }^{16}$ The Federal Open Market Committee announced a $\$ 400$ billion program in September 2011 and an additional $\$ 267$ billion program in June 2012 through the end of 2012.
} 
previous section, the AFNS and its mixtures with other models, which are associated with very strong positive correlations across different maturities, would not perform well during the period of Operation Twist and our empirical evidence confirms this conjecture.

We also consider the relative forecasting performance of $N A R_{M S}$ against the RW benchmark model because $N A R_{M S}$ has the highest frequency of being included in the MCSs across different maturities at different forecasting horizons during the conventional monetary policy period. Figure 2 shows that the RW performed very well during the unconventional monetary policy period, as depicted in Figure $1 .{ }^{17}$

\section{Conclusion}

Compared with conventional monetary policy, unconventional policy in the low interest rate environment since the Great Recession has a different transmission mechanism to the term structure of interest rates. We study how conventional and unconventional monetary policies affect the forecasting performance of individual yield curve models and their mixtures.

Out-of-sample forecasts for U.S. bond yields show that the arbitrage-free Nelson-Siegel model and its mixtures perform well in the period of conventional monetary policy, whereas the random walk model outperforms all the individual models and their mixtures in the period of unconventional monetary policy period.

We find that the cross-equation restrictions for yields implied by the arbitrage-free NelsonSiegel model are associated with high correlations of bond yields across different maturities. The diminished usefulness of no-arbitrage restrictions in forecasting the yield curve since 2009 can be attributed to unconventional monetary policy, which involved direct purchases of long-term bonds while the short-term bond yields were stuck near zero, resulting in low correlations between short- and long-term bond yields and little variation in short-term rates. As a result, the RW model performs well in the period of unconventional monetary policy and its more pronounced superiority during the maturity extension program in 2011-2012 further supports our finding because the program moved short- and long-term bond yields in opposite directions. We also emphasize that our findings are potentially useful in predicting the bond yields in the current low interest rate environment, where unconventional monetary

\footnotetext{
${ }^{17} \mathrm{We}$ conduct the same analysis with a recursive (expanding) window and find that the results are largely consistent. See the online appendix for the details.
} 
policy may recur in the near future. 


\section{References}

Aiolfi, Marco, and Allan Timmermann. 2006. "Persistence in forecasting performance and conditional combination strategies." Journal of Econometrics, 135(1-2): 31-53.

Almeida, Caio, and Jose Vicente. 2008. "The role of no-arbitrage on forecasting: Lessons from a parametric term structure model." Journal of Banking and Finance, 32(12): 26952705.

Ang, Andrew, and Geert Bekaert. 2002. "Short rate nonlinearities and regime switches." Journal of Economic Dynamics and Control, 26(7-8): 1243-1274.

Ang, Andrew, and Monika Piazzesi. 2003. "A no-arbitrage vector autoregression of term structure dynamics with macroeconomic and latent variables." Journal of Monetary economics, 50(4): 745-787.

Bansal, Ravi, and Hao Zhou. 2002. "Term structure of interest rates with regime shifts." Journal of Finance, 57(5): 1997-2043.

Bernardi, Mauro, and Leopoldo Catania. 2018. "The model confidence set package for R." International Journal of Computational Economics and Econometrics, 8(2): 144-158.

Carriero, Andrea, and Raffaella Giacomini. 2011. "How useful are no-arbitrage restrictions for forecasting the term structure of interest rates?" Journal of Econometrics, 164(1): 2134.

Chib, S., and B. Ergashev. 2009. "Analysis of multi-factor affine yield curve Models." Journal of the American Statistical Association, 104(488): 1324-1337.

Chib, S., and K. H. Kang. 2013. "Change Points in Affine Arbitrage-free Term Structure Models." Journal of Financial Econometrics, 11(2): 302-334.

Christensen, Jens H. E., Francis X. Diebold, and Glenn D. Rudebusch. 2011. "The affine arbitrage-free class of Nelson-Siegel term structure models." Journal of Econometrics, 164: 4-20.

Christensen, Jens HE, and Glenn D Rudebusch. 2017. "A new normal for interest rates? Evidence from inflation-indexed debt." Review of Economics and Statistics, 1-46.

Dai, Qiang, Kenneth J. Singleton, and Wei Yang. 2007. "Regime shifts in a dynamic term structure model of U.S. treasury bond yields." Review of Financial Studies, 20: 1669-1706. 
Deutsch, Melinda, Clive WJ Granger, and Timo Teräsvirta. 1994. "The combination of forecasts using changing weights." International Journal of Forecasting, 10(1): 47-57.

Diebold, F. X., and C. L. Li. 2006. "Forecasting the term structure of government bond yields." Journal of Econometrics, 130: 337-364.

Diebold, F. X., Glenn Rudebusch, and S. B. Aruoba. 2006. "The macroeconomy and the yield curve: a dynamic latent factor approach." Journal of Econometrics, 131: 309-338.

Diebold, Francis X, and Peter Pauly. 1987. "Structural change and the combination of forecasts." Journal of Forecasting, 6(1): 21-40.

Duffie, Darrell, and Rui Kan. 1996. "A yield-factor model of interest rates." Mathematical Finance, 6: 379-406.

Elliott, Graham, and Allan Timmermann. 2005. "Optimal forecast combination under regime switching." International Economic Review, 46(4): 1081-1102.

Geweke, John, and Gianni Amisano. 2011. "Optimal prediction pools." Journal of Econometrics, 164(1): 130-141.

Geweke, John, and Gianni Amisano. 2012. "Prediction with Misspecified Models." American Economic Review, 102(3): 482-486.

Granger, Clive WJ, and Paul Newbold. 1973. "Some comments on the evaluation of economic forecasts." Applied Economics, 5(1): 35-47.

Guidolin, Massimo, and Allan Timmermann. 2007. "Asset allocation under multivariate regime switching." Journal of Economic Dynamics and Control, 31(11): 3503-3544.

Guidolin, Massimo, and Allan Timmermann. 2009. "Forecasts of US short-term interest rates: A flexible forecast combination approach." Journal of Econometrics, 150(2): 297311.

Guidolin, Massimo, and Manuela Pedio. 2019. "Forecasting and Trading Monetary Policy Effects on the Riskless Yield Curve with Regime Switching Nelson-Siegel Models." Journal of Economic Dynamics and Control, forthcoming.

Gürkaynak, Refet S, Brian Sack, and Eric Swanson. 2005. "The sensitivity of long-term interest rates to economic news: Evidence and implications for macroeconomic models." American economic review, 95(1): 425-436. 
Hamilton, James D, Ethan S Harris, Jan Hatzius, and Kenneth D West. 2016. "The equilibrium real funds rate: Past, present, and future." IMF Economic Review, 64(4): 660-707.

Hansen, Peter R, Asger Lunde, and James M Nason. 2011. "The model confidence set." Econometrica, 79(2): 453-497.

Hansen, Peter R, Asger Lunde, and James M Nason. 2014. "Corrigendum to The model confidence set." manuscript.

Hevia, Constantino, Martin Gonzalez-Rozada, Martin Sola, and Fabio Spagnolo. 2015. "Estimating and forecasting the yield curve using a Markov switching dynamic Nelson and Siegel model." Journal of Applied Econometrics, 30(6): 987-1009.

Inoue, Atsushi, and Barbara Rossi. 2018. "The Effects of Conventional and Unconventional Monetary Policy: A New Approach." Manuscript, Vanderbilt University and Pompeu Fabra.

Kiley, Michael T, and John M Roberts. 2017. "Monetary policy in a low interest rate world." Brookings Papers on Economic Activity, 2017(1): 317-396.

Kuttner, Kenneth N. 2001. "Monetary policy surprises and interest rates: Evidence from the Fed funds futures market." Journal of monetary economics, 47(3): 523-544.

Laubach, Thomas, and John C Williams. 2016. "Measuring the natural rate of interest redux." Business Economics, 51(2): 57-67.

Levant, Jared, and Jun Ma. 2017. "A dynamic Nelson-Siegel yield curve model with Markov switching." Economic Modelling, 67: 73-87.

Moench, E. 2008. "Forecasting the yield curve in a data-rich environment: A no-arbitrage factor-augmented VAR approach." Journal of Econometrics, 146: 26-43.

Nelson, Charles R, and Andrew F Siegel. 1987. "Parsimonious modeling of yield curves." Journal of Business, 473-489.

Niu, Linlin, and Gengming Zeng. 2012. "The Discrete-Time Framework of Arbitrage-Free Nelson-Siegel Class of Term Structure Models." manuscript, 1-68.

Pescatori, Andrea, and Jarkko Turunen. 2016. "Lower for longer: Neutral rate in the US." IMF Economic Review, 64(4): 708-731.

Romer, Christina D, and David H Romer. 2004. "A new measure of monetary shocks: Derivation and implications." American Economic Review, 94(4): 1055-1084. 
Swanson, Eric T, and John C Williams. 2014. "Measuring the effect of the zero lower bound on medium-and longer-term interest rates." American Economic Review, 104(10): 3154-85.

Waggoner, Daniel, and Tao Zha. 2012. "Confronting model misspecification in macroeconomics." Journal of Econometrics, 171(2): 167-184.

Wright, Jonathan H. 2012. "What does monetary policy do to long-term interest rates at the zero lower bound?" The Economic Journal, 122(564): F447-F466.

Zantedeschi, Daniel, Paul Damien, and Nicholas G. Polson. 2011. "Predictive MacroFinance With Dynamic Partition Models." Journal of the American Statistical Association, 106(494): 427-439. 


\section{Online Appendix for "The Effects of Conventional and Unconventional Monetary Policy on Forecasting the Yield Curve"}

\author{
Yunjong Eo* \\ University of Sydney \\ Kyu Ho Kang ${ }^{\dagger}$ \\ Korea University
}

September 26, 2019

This supplement gives details about the estimation procedure and additional empirical results.

\section{A Estimation}

\section{A.1 Likelihood Function Construction}

This section presents the step-by-step procedure for the log-likelihood calculation. Suppose that $\boldsymbol{\psi}$ is the set of all model parameters and the $\log$-likelihood $\log L$ is initialized to zero. At time $1, p\left(s_{t-1} \mid Y_{t-1}, \boldsymbol{\psi}\right)$ is given at the unconditional probability of regime $s_{t}$. For $t=1,2, . ., T$, the following steps are repeated sequentially.

Algorithm 1: Log-likelihood calculation

- Step 1: The predictive probability of regime $s_{t}, p\left(s_{t}=j \mid Y_{t-1}, \boldsymbol{\psi}\right)$ is computed as

$$
\begin{aligned}
p\left(s_{t}\right. & \left.=j \mid Y_{t-1}, \boldsymbol{\psi}\right) \\
& =\sum_{i=1}^{2} \operatorname{Pr}\left[s_{t}=j \mid s_{t-1}=i, \boldsymbol{\psi}\right] \times \operatorname{Pr}\left(s_{t-1}=i \mid Y_{t-1}, \boldsymbol{\psi}\right) \\
& =\sum_{i=1}^{2} q_{i j} \times p\left(s_{t-1}=i \mid Y_{t-1}, \boldsymbol{\psi}\right), \quad j=1,2 .
\end{aligned}
$$

${ }^{*}$ School of Economics, University of Sydney, NSW 2006, Australia; E-mail: yunjong.eo@sydney.edu.au

${ }^{\dagger}$ Department of Economics, Korea University, Seoul, South Korea, 136-701; E-mail: kyuho@korea.ac.kr 
- Step 2: The predictive model weight on $\mathcal{M}_{1}, w_{1, s_{t}}$ is given by

$$
W_{1, t}=\sum_{s_{t}=1}^{2} w_{1, s_{t}} \times p\left(s_{t} \mid Y_{t-1}^{o}, \boldsymbol{\psi}\right),
$$

such that the predictive model weight on $\mathcal{M}_{2}$ is $W_{2, t}=1-W_{1, t}$.

- Step 3: We now have the conditional likelihood density $p\left(\mathbf{y}_{t} \mid Y_{t-1}, \boldsymbol{\psi}\right)$, given by

$$
W_{1, t} \times p\left(\mathbf{y}_{t} \mid Y_{t-1}, \Theta_{1}, \mathcal{M}_{1}\right)+W_{2, t} \times p\left(\mathbf{y}_{t} \mid Y_{t-1}, \Theta_{2}, \mathcal{M}_{2}\right),
$$

and $\log L=\log L+\log p\left(\mathbf{y}_{t} \mid Y_{t-1}, \boldsymbol{\psi}\right)$.

- Step 4: The updated probability of regime $s_{t}, p\left(s_{t}=i \mid Y_{t}, \boldsymbol{\psi}\right)$ is calculated and retained as

$$
\begin{aligned}
p\left(s_{t}\right. & \left.=i \mid Y_{t}, \boldsymbol{\psi}\right) \\
& =p\left(s_{t}=i \mid Y_{t-1}, \boldsymbol{\psi}, \mathbf{y}_{t}\right) \\
& =\frac{p\left(s_{t}=i, \mathbf{y}_{t} \mid Y_{t-1}, \boldsymbol{\psi}\right)}{p\left(\mathbf{y}_{t} \mid Y_{t-1}, \boldsymbol{\psi}\right)} \\
& =\frac{p\left(\mathbf{y}_{t} \mid Y_{t-1}, \boldsymbol{\psi}, s_{t}=i\right) p\left(s_{t}=i \mid Y_{t-1}, \boldsymbol{\psi}\right)}{p\left(\mathbf{y}_{t} \mid Y_{t-1}, \boldsymbol{\psi}\right)} \text { for } i=1,2,
\end{aligned}
$$

where the predictive density of $y_{t}$ given $s_{t}$ is simply given by

$$
\begin{aligned}
& p\left(\mathbf{y}_{t} \mid Y_{t-1}, \boldsymbol{\psi}, s_{t}\right) \\
= & w_{1, s_{t}} \times p\left(\mathbf{y}_{t} \mid Y_{t-1}, \Theta_{1}, \mathcal{M}_{1}\right)+\left(1-w_{1, s_{t}}\right) \times p\left(\mathbf{y}_{t} \mid Y_{t-1}, \Theta_{2}, \mathcal{M}_{2}\right) .
\end{aligned}
$$

- Step 5: Set $t=t+1$ and go to Step 1 if $t \leq T$.

\section{A.2 Prior}

Table A.1 summarizes our prior distributions, and Figure A.1 depicts the mean of the resulting prior-implied unconditional distribution of the yield curve, which is mildly upward sloping and concave. Note that $\phi$ for the DNS and $G$ for the AFNS are diagonal, because these restrictions help to improve the predictive accuracy and reduces the computational burden, as shown in Christensen, Diebold and Rudebusch (2011).

For the regime identification, we impose the restriction that for any Markov-switching combinations involving the DNS model, the weight on the DNS model $\mathcal{M}_{N S}$, denoted by 
$w_{N S, s_{t}}$, should be higher in regime 2 than it is in regime 1 :

$$
0<w_{N S, s_{t}=1}<w_{N S, s_{t}=2}<1
$$

where $w_{A F, s_{t}}$ is the weight on the AFNS model. For the $A R_{M S}$ model, which does not include the DNS model, the restriction is replaced by

$$
0<w_{A F, s_{t}=1}<w_{A F, s_{t}=2}<1 .
$$

All of the restrictions, including those on the factor identification and regime identification, are imposed through the prior.

Figure A.1: Prior-implied Unconditional Distribution of the Yield Curve

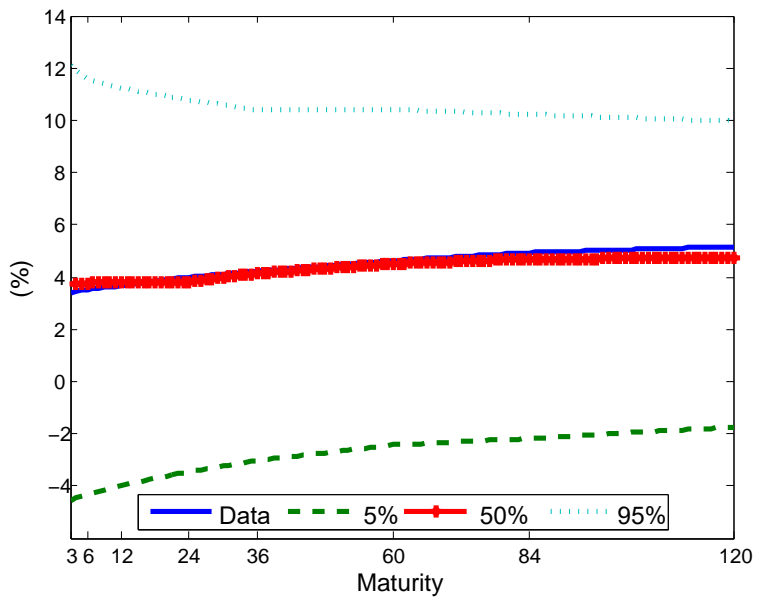

(a) DNS

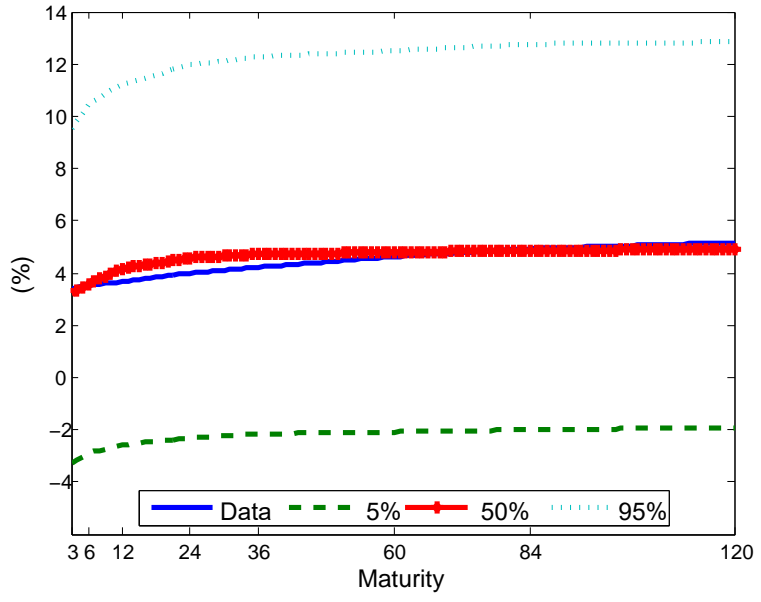

(b) AFNS

Note: We plot the 5\%,50\%, and $95 \%$ quantiles for the distribution of the prior-implied yield curve for each model against the historical mean of the yield curve (blue solid line) for the data from February 1994 to December 2013.

\section{A.3 Posterior Sampling}

Parameter Sampling In this appendix, we discuss each MCMC step in detail. First, $\Theta=\left(\Theta_{N S}, \Theta_{A F}, \Theta_{R W}, w\right)$ are simulated using a tailored randomized blocking MetropolisHastings algorithm (TaRB-MH, Chib and Ramamurthy (2010)). Note that the posterior 
Table A.1: Prior distributions

\begin{tabular}{lccc}
\hline \hline Parameter & Density & Mean & S.D. \\
\hline $1200 \times \kappa$ & Normal & $(0.2,-0.1,-0.1)^{\prime}$ & $(0.01,0.01,0.01)^{\prime}$ \\
$\operatorname{diag}(\phi)$ & Normal & $(0.9,0.9,0.9)^{\prime}$ & $(0.05,0.05,0.05)^{\prime}$ \\
$1200 \times \operatorname{diag}\left(V_{N S}\right)$ & Inv. Gamma & 1.000 & 0.200 \\
$\rho_{N S, i j}(i \neq j, i, j=1,2,3)$ & Uniform & 0.000 & 0.580 \\
$1.4 \times 10^{4} \times \operatorname{diag}\left(\Sigma_{N S}\right)$ & Inv. Gamma & 2.000 & 0.300 \\
\hline
\end{tabular}

(a) DNS

\begin{tabular}{lccc}
\hline \hline Parameter & Density & Mean & S.D. \\
\hline $\bar{\gamma}$ & Normal & $(-0.15,-0.07,0)^{\prime}$ & $(0.01,0.01,0.01)^{\prime}$ \\
$\boldsymbol{g}^{Q}$ & Normal & 0.067 & 0.031 \\
$\operatorname{diag}(G)$ & Normal & $(0.9,0.9,0.9)^{\prime}$ & $(0.05,0.05,0.05)^{\prime}$ \\
$10^{4} \times \operatorname{diag}\left(V_{A F}\right)$ & Inv. Gamma & $(2,2.5,5)^{\prime}$ & $(0.25,0.25,0.25)^{\prime}$ \\
$\rho_{A F, i j}(i \neq j, i, j=1,2,3)$ & Uniform & 0.000 & 0.580 \\
$1.4 \times 10^{4} \times \operatorname{diag}\left(\Sigma_{A F}\right)$ & Inv. Gamma & 2.000 & 0.300 \\
\hline
\end{tabular}

(b) AFNS

\begin{tabular}{lccc}
\hline \hline Parameter & Density & Mean & S.D. \\
\hline $1.4 \times 10^{4} \times \operatorname{diag}\left(\Sigma_{R W}\right)$ & Inv. Gamma & 2.000 & 0.300 \\
\hline
\end{tabular}

(c) Random walk

\begin{tabular}{llll}
\hline \hline Parameter & Density & Mean & S.D. \\
\hline$w_{i, s_{t}}\left(s_{t}=1,2\right)$ & Uniform & 0.500 & 0.29 \\
& (d) Model weight \\
\hline \hline Parameter & Density & Mean & S.D. \\
\hline$q_{i i}(i=1,2)$ & Beta & 0.900 & 0.05 \\
\hline
\end{tabular}

(e) Transition probability

Note: $\Theta_{N S}=\left\{\kappa, \phi, \Sigma_{N S}, \Omega_{N S}=V_{N S} \Gamma_{N S} V_{N S}\right\}$ and $\Theta_{A F}=\left\{G, g^{Q}, \Sigma_{A F}, \Omega_{A F}=V_{A F} \Gamma_{A F} V_{A F}\right\}$ are the parameters of the models DNS and AFNS, respectively. $V_{N S}$ and $V_{A F}$ are the factor volatilities, and $\Gamma_{N S}$ and $\Gamma_{A F}$ are the correlation matrices. $\rho_{N S, i j}$ and $\rho_{A F, i j}$ are the $(i, j)$ elements of $\Gamma_{N S}$ and $\Gamma_{A F}$, respectively.

density of $\Theta$ is proportional to the product of the likelihood and the prior because

$$
\pi(\Theta \mid \mathbf{Y}, Q) \propto f(\mathbf{Y} \mid \boldsymbol{\psi}) \times \pi(\Theta)
$$


We simulate $\Theta \mid \mathbf{Y}, Q$ rather than $\Theta \mid \mathbf{Y}, \mathbf{S}, \mathbf{X}, Q$ by integrating out the regimes and the latent factors because the former is more efficient than the latter. The likelihood computation is illustrated in Appendix A.1.

In every MCMC iteration, we apply the TaRB-MH method and sample $\Theta$ given $(\mathbf{Y}, Q)$. This algorithm is particularly useful when the posterior density is high-dimensional and its surface is possibly irregular. There are two key ideas in the method. One is to construct student-t proposal distributions whose mode and scale are obtained from a stochastic optimization combined with a Newton-Raphson method. The other is to randomize the blocks over the MCMC iterations, given that it is difficult to group the parameters such that the parameters in different blocks are not highly correlated. In other words, the randomized blocks of $\Theta$ are sequentially updated by the multiple-block MH algorithm, where the proposal value for each block is generated from the Student-t distribution. For more technical details, refer to Chib and Ramamurthy (2010).

Next, because the transition probability $Q$ is independent of $(\mathbf{Y}, \Theta)$, it is sampled from

$$
Q \mid \mathbf{S}
$$

given the regimes $\mathbf{S}$, Moreover, its prior is conjugate and the transition probabilities are sampled from a beta distribution.

Regime Sampling The time-series of the regimes $\mathbf{S}$ is simulated in one block using the multi-move method (Chib (1998)). This method consists of two stages. The first stage calculates the filtered probabilities, $\operatorname{Pr}\left(s_{t} \mid Y_{t}, \boldsymbol{\psi}\right)$, as follows:

$$
\begin{aligned}
\operatorname{Pr}\left(s_{t}\right. & \left.=j \mid Y_{t}, \boldsymbol{\psi}\right)=\frac{\sum_{i=1}^{2} p\left(\mathbf{y}_{t} \mid Y_{t-1}, s_{t}=j, \boldsymbol{\psi}\right) \times \operatorname{Pr}\left(s_{t}=j \mid s_{t-1}=i, \boldsymbol{\psi}\right)}{\sum_{j=1}^{2}\left[\sum_{i=1}^{2} p\left(\mathbf{y}_{t} \mid Y_{t-1}, s_{t}=j, \boldsymbol{\psi}\right) \times \operatorname{Pr}\left(s_{t}=j \mid s_{t-1}=i, \boldsymbol{\psi}\right)\right]} \\
& =\frac{\sum_{i=1}^{2} p\left(\mathbf{y}_{t} \mid Y_{t-1}, s_{t}=j, \boldsymbol{\psi}\right) \times q_{i j}}{\sum_{j=1}^{2}\left[\sum_{i=1}^{2} p\left(\mathbf{y}_{t} \mid Y_{t-1}, s_{t}=j, \boldsymbol{\psi}\right) \times q_{i j}\right]}
\end{aligned}
$$

for $j=1,2$. Then, the conditional density of $\mathbf{y}_{t} p\left(\mathbf{y}_{t} \mid Y_{t-1}, s_{t}, \boldsymbol{\psi}\right)$ is computed as a linear combination of the model-specific conditional densities of $\mathbf{y}_{t}: p\left(\mathbf{y}_{t} \mid Y_{t-1}, \Theta_{N S}, \mathcal{M}_{N S}\right)$, $p\left(\mathbf{y}_{t} \mid Y_{t-1}, \Theta_{A F}, \mathcal{M}_{A F}\right)$, and $p\left(\mathbf{y}_{t} \mid Y_{t-1}, \Theta_{R W}, \mathcal{M}_{R W}\right)$. That is,

$$
\begin{aligned}
& p\left(\mathbf{y}_{t} \mid Y_{t-1}, s_{t}, \boldsymbol{\psi}\right) \\
= & w_{N S, s_{t}} \times p\left(\mathbf{y}_{t} \mid Y_{t-1}, \Theta_{N S}, \mathcal{M}_{N S}\right)+w_{A F, s_{t}} \times p\left(\mathbf{y}_{t} \mid Y_{t-1}, \Theta_{A F}, \mathcal{M}_{A F}\right) \\
& +\left(1-w_{N S, s_{t}}-w_{A F, s_{t}}\right) \times p\left(\mathbf{y}_{t} \mid Y_{t-1}, \Theta_{R W}, \mathcal{M}_{R W}\right) .
\end{aligned}
$$


These model-specific conditional densities are already given in Section 2 of the main text.

In the second stage, $\left\{s_{t}\right\}_{t=1}^{T}$ is sampled using backward recursion. The regime at time $T$, $s_{T}$, is first drawn with the filtered probability $\operatorname{Pr}\left(s_{T} \mid Y_{T}, \boldsymbol{\psi}\right)$. Then, conditioned on $s_{t+1}$, we compute $\operatorname{Pr}\left(s_{t} \mid Y_{t}, s_{t+1}, \boldsymbol{\psi}\right)$ using the filtered probabilities, as follows:

$$
\begin{aligned}
\operatorname{Pr}\left(s_{t}\right. & \left.=i \mid Y_{t}, s_{t+1}, \boldsymbol{\psi}\right) \\
& =\frac{q_{i j} \times \operatorname{Pr}\left[s_{t}=i \mid Y_{t}, \boldsymbol{\psi}\right]}{\sum_{i=1}^{2} q_{i j} \times \operatorname{Pr}\left[q_{t}=i \mid Y_{t}, \boldsymbol{\psi}\right]}, i=1,2 .
\end{aligned}
$$

Now, given $s_{t+1}, s_{t}$ is sampled with the probability $\operatorname{Pr}\left(s_{t} \mid Y_{t}, s_{t+1}, \boldsymbol{\psi}\right)$ for $t=T-1, T-2, . ., 1$, which completes the regime sampling.

Factor Sampling Using the one-to-one mapping between the factors and basis yields, the factors are obtained as $\mathbf{f}_{t}=\left(\mathbf{b}_{B}\right)^{-1} \times\left(\mathbf{y}_{t}^{B}-\mathbf{a}_{B}\right)$ and $\mathbf{x}_{t}=\left(\boldsymbol{\Lambda}_{B}\right)^{-1} \times \mathbf{y}_{t}^{B}$ for each $t$ given the model parameters and bond yields.

Predictive Yield Curve Sampling Each MCMC cycle is completed by sampling the posterior predictive draws, given $(\mathbf{Y}, \mathbf{X}, \mathbf{F}, \mathbf{S}, \boldsymbol{\psi})$. For each posterior draw, $\left(\mathbf{y}_{T}, \mathbf{x}_{T}, \mathbf{f}_{T}, s_{T}, \boldsymbol{\psi}\right)$, and a forecast horizon of $h=1,2, . ., H$, we first simulate the predictive draws of the factors $\left\{\mathbf{x}_{T+h}, \mathbf{f}_{T+h}\right\}_{h=1}^{H}$. Given the factors and parameters, the model-specific predictive bond yields are generated within the individual model specifications. Next, the predictive regime $\left\{s_{T+h}\right\}_{h=1}^{H}$ is sampled using the Markov-switching process. This regime determines the model weights for each forecast horizon. Finally, the predictive yield curve is computed as a linear combination of the model-specific predictive yield curves and is retained as a posterior predictive draw. The following algorithm summarizes the predictive yield curve simulation.

\section{Algorithm 2: Posterior predictive distribution simulation}

- Step 1: Sample the factors $\left\{\mathbf{x}_{T+h}\right\}_{h=1}^{H} \mid \mathbf{X}, \Theta_{N S}$ and $\left\{\mathbf{f}_{T+h}\right\}_{h=1}^{H} \mid \mathbf{F}, \Theta_{A F}$.

- Step 2: Sample the model-specific predictive yields

$$
\left\{\mathbf{y}_{N S, T+h}\right\}_{h=1}^{H}\left|\mathbf{X}, \Theta_{N S}, \quad\left\{\mathbf{y}_{A F, T+h}\right\}_{h=1}^{H}\right| \mathbf{F}, \Theta_{A F}, \text { and }\left\{\mathbf{y}_{R W, T+h}\right\}_{h=1}^{H} \mid \mathbf{Y}, \Theta_{R W} .
$$

- Step 3: Sample the predictive regimes, $\left\{s_{T+h}\right\}_{h=1}^{H} \mid \mathbf{S}, Q$.

- Step 4: For $h=1,2, . ., H$, compute the predictive yield curve as

$$
\begin{aligned}
\mathbf{y}_{T+h}= & w_{N S, s_{T+h}} \times \mathbf{y}_{N S, T+h}+w_{A F, s_{T+h}} \times \mathbf{y}_{A F, T+h} \\
& +\left(1-w_{N S, s_{T+h}}-w_{A F, s_{T+h}}\right) \times \mathbf{y}_{R W, T+h} .
\end{aligned}
$$


- Step 5: Retain $\left\{\mathbf{y}_{T+h}\right\}_{h=1}^{H}$ as a posterior predictive draw.

\section{B Forecasting Evaluations with the Recursive Window}

In the main text, we produce the forecasts based on the rolling window with its length of 120 months. We replicate our analysis based on a recursive (expanding) window. ${ }^{1}$ For easier comparison, Figure B.1 plots the cumulative squared forecasting errors of the RW minus the cumulative squared forecasting errors of the AFNS over time based on the recursive window against those for the rolling window. We find that the results are largely consistent regardless of the window schemes.

Figure B.2 compares the RW with the $\mathrm{NAR}_{M S}$ in the same way for the two window schemes. The superiority of the RW at 1-month-ahead horizon in the period of unconventional monetary policy is less pronounced with the recursive window compared to the rolling window. This seems to be because, as the sample size for estimation gets larger with the recursive window, the regime-switching process is more likely to identify the regime shifts in the yield curve dynamics associated with changes in monetary policy. Meanwhile, the forecasting performance of $\mathrm{NAR}_{M S}$ at long forecast horizons is still poor because of the inefficiency in predicting the regimes at long forecast horizons. Finally, we find similar pattern that the RW appears to perform well since 2009.

\section{Factor Loadings}

Figure C.1 compares the factor loadings of the DNS and AFNS models estimated from the rolling and recursive windows. The AFNS factor loadings show no drastic changes over time. This means that the factor loadings are too restrictive to detect changes in the correlations among the bond yields in the period of unconventional monetary policy. In addition, the AFNS factor loadings appear to be very similar to those of the DNS model. However, the noarbitrage condition in the AFNS is imposed by the restrictions on the parameters associated with the factor dynamics as well as the factor loadings while the parameters associated with the DNS's factor dynamics are estimated without any restriction. These additional restrictions particularly help the AFNS improve upon the DNS in the period of conventional monetary policy as shown in the main text.

\footnotetext{
${ }^{1}$ We thank an anonymous referee for suggesting this analysis.
} 
Figure B.1: AFNS vs. RW: Difference in cumulative mean squared forecasting errors
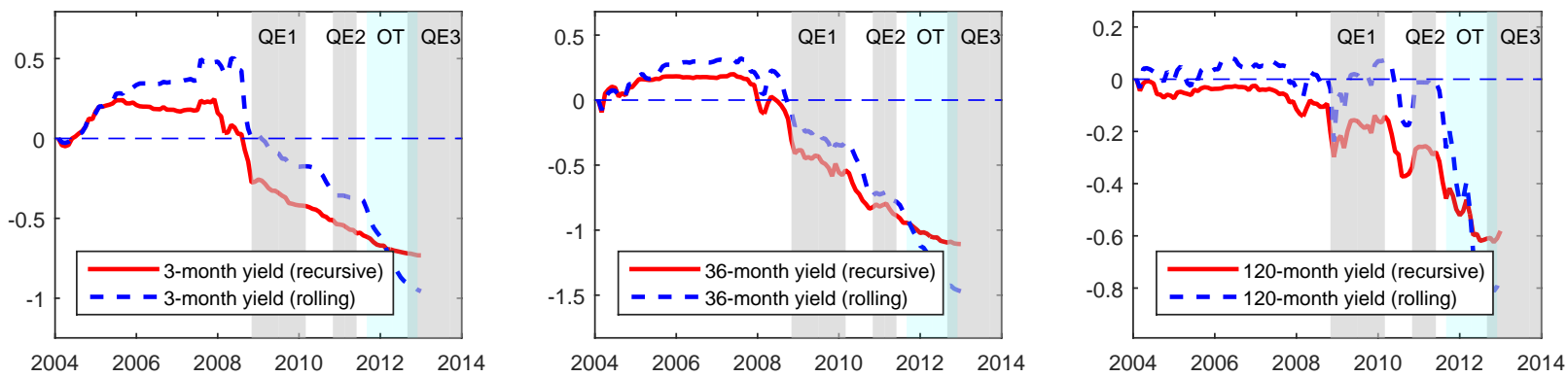

(a) 1-month-ahead forecasts
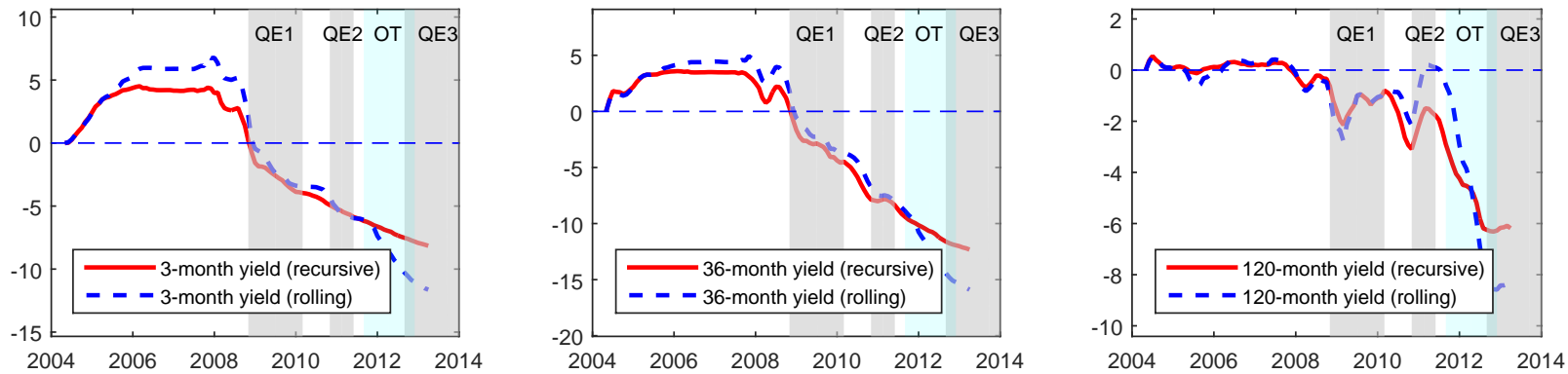

(b) 4-month-ahead forecasts
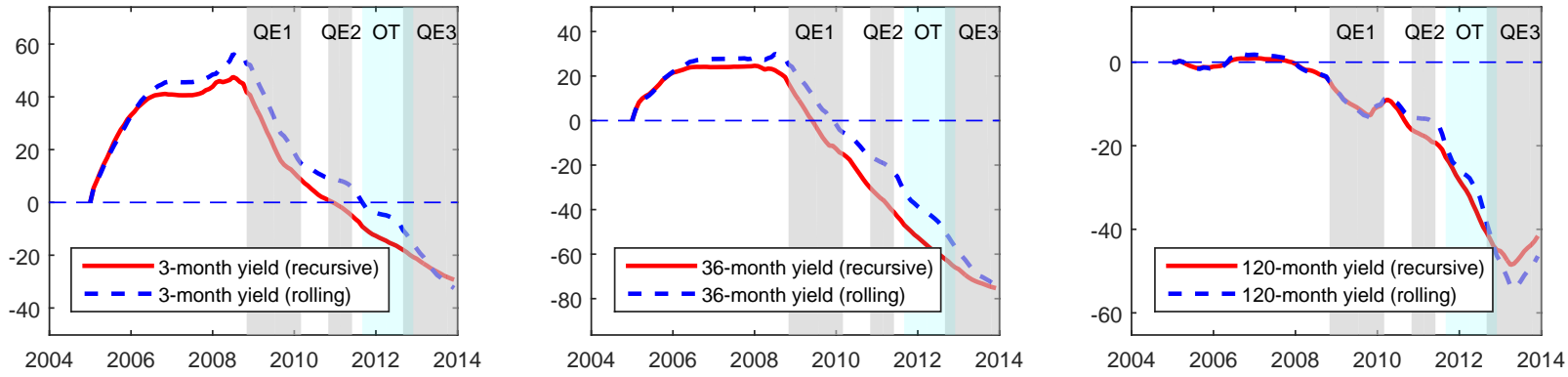

(c) 12-month-ahead forecasts

Note: We plot the cumulative mean squared forecasting errors of the random walk model $(R)$ minus the cumulative mean squared forecasting errors of the arbitrage-free Neslon-Siegel Model $(A): \sum_{s=1}^{t}\left[L_{R, s}(\tau, h)-L_{A, s}(\tau, h)\right]$. The x-axis indicates time $t+h$. Whenever a line increases, the arbitrage-free Nelson-Siegel model forecasts better; whenever it decreases, the random walk model forecasts better. The grey shaded areas correspond to three quantitative easing programs QE1, QE2, and QE3; and the blue shaded area corresponds to the maturity extension program, also known as the second "Operation Twist (OT)". There is overlap between OT and QE3 from September 2012 to December 2012. 
Figure B.2: $N A R_{M S}$ vs. RW: Difference in cumulative mean squared forecasting errors
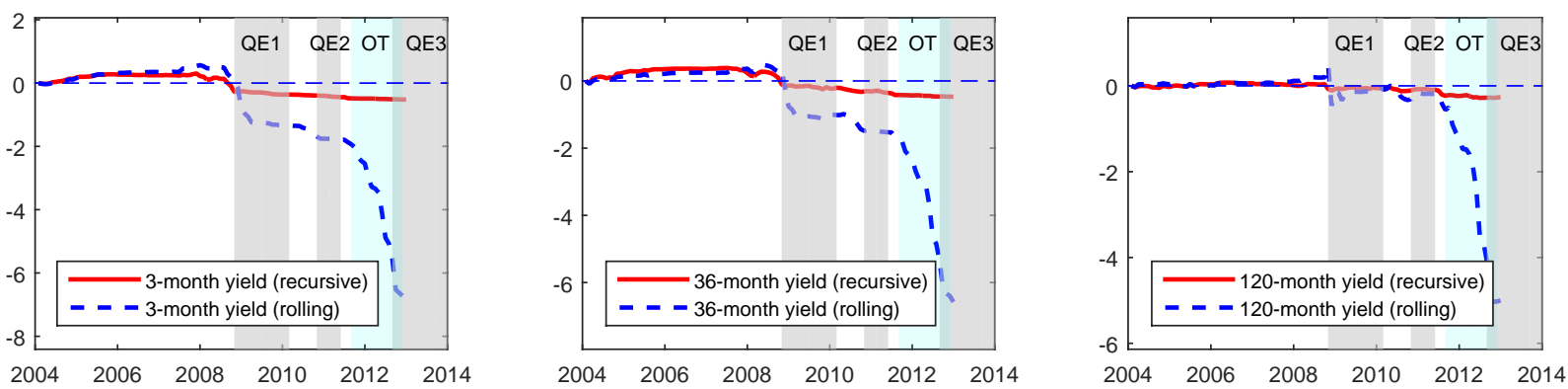

(a) 1-month-ahead forecasts
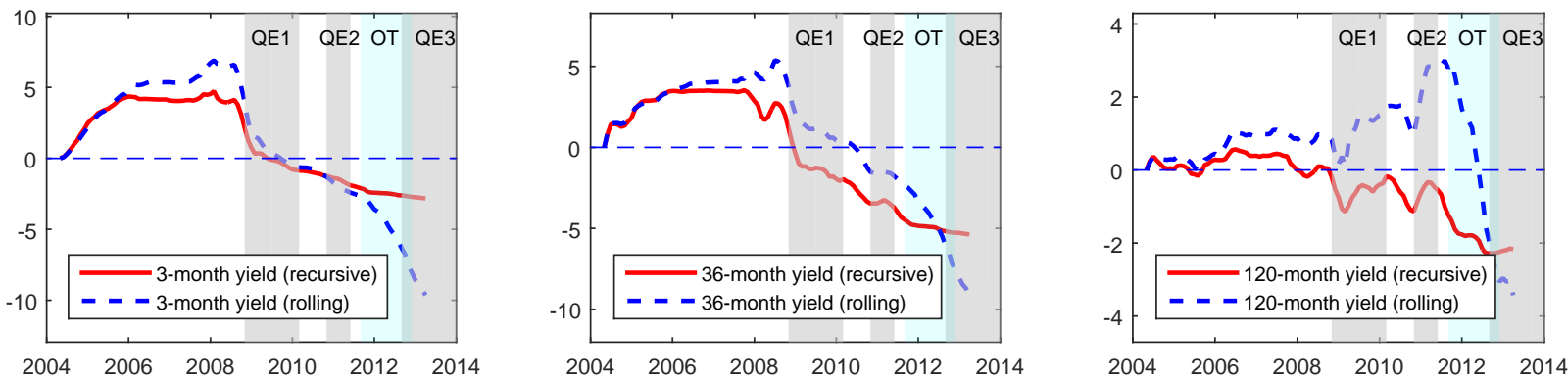

(b) 4-month-ahead forecasts
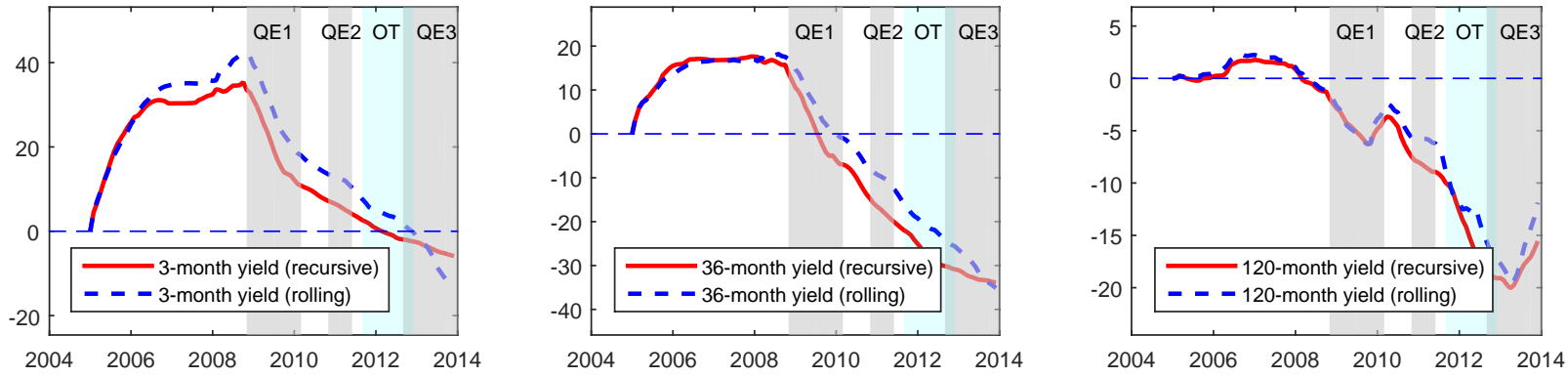

(c) 12-month-ahead forecasts

Note: We plot the cumulative mean squared forecasting errors of the random walk model $(R)$ minus the cumulative mean squared forecasting errors of the Markov-switching mixture of three models $\left(N A R_{M S}\right): \sum_{s=1}^{t}\left[L_{R, s}(\tau, h)-L_{N A R_{M S}, s}(\tau, h)\right]$. The x-axis indicates time $t+h$. Whenever a line increases, $N A R_{M S}$ forecasts better; whenever it decreases, $R$ forecasts better. The grey shaded areas correspond to three quantitative easing programs QE1, QE2, and QE3; and the blue shaded area corresponds to the maturity extension program, also known as the second "Operation Twist (OT)". There is overlap between OT and QE3 from September 2012 to December 2012. 
Figure C.1: Factor loadings
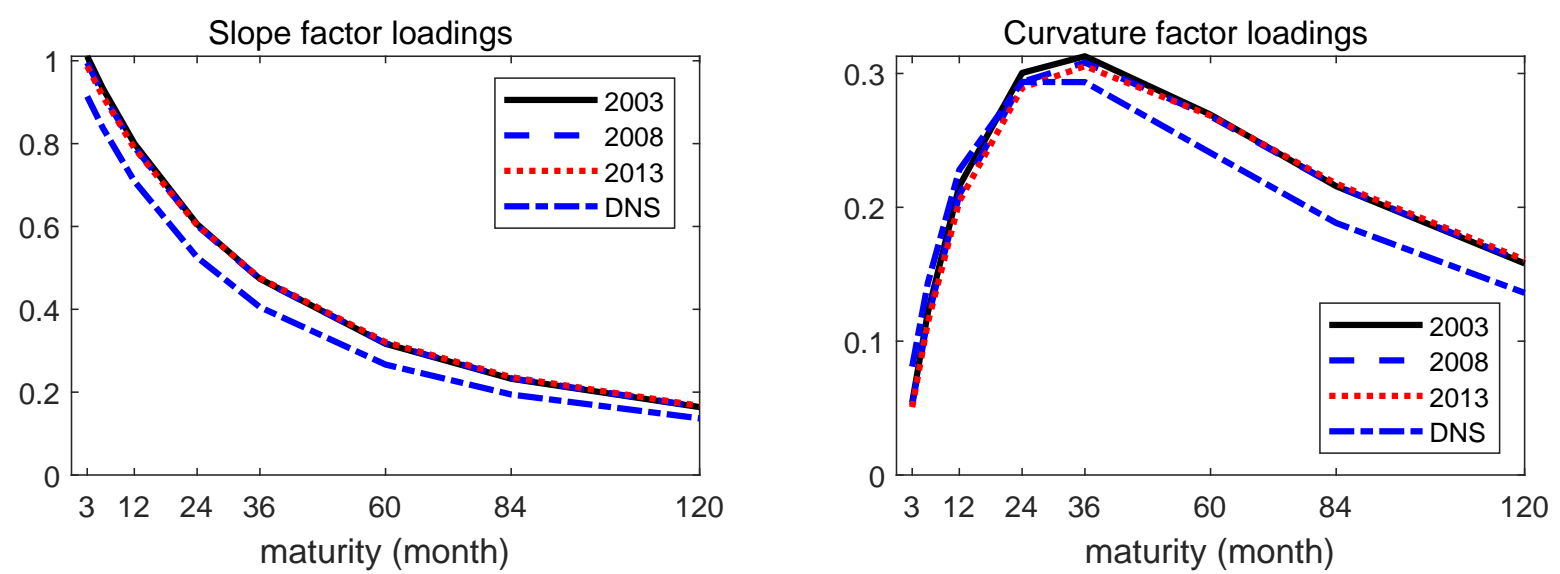

(a) rolling window
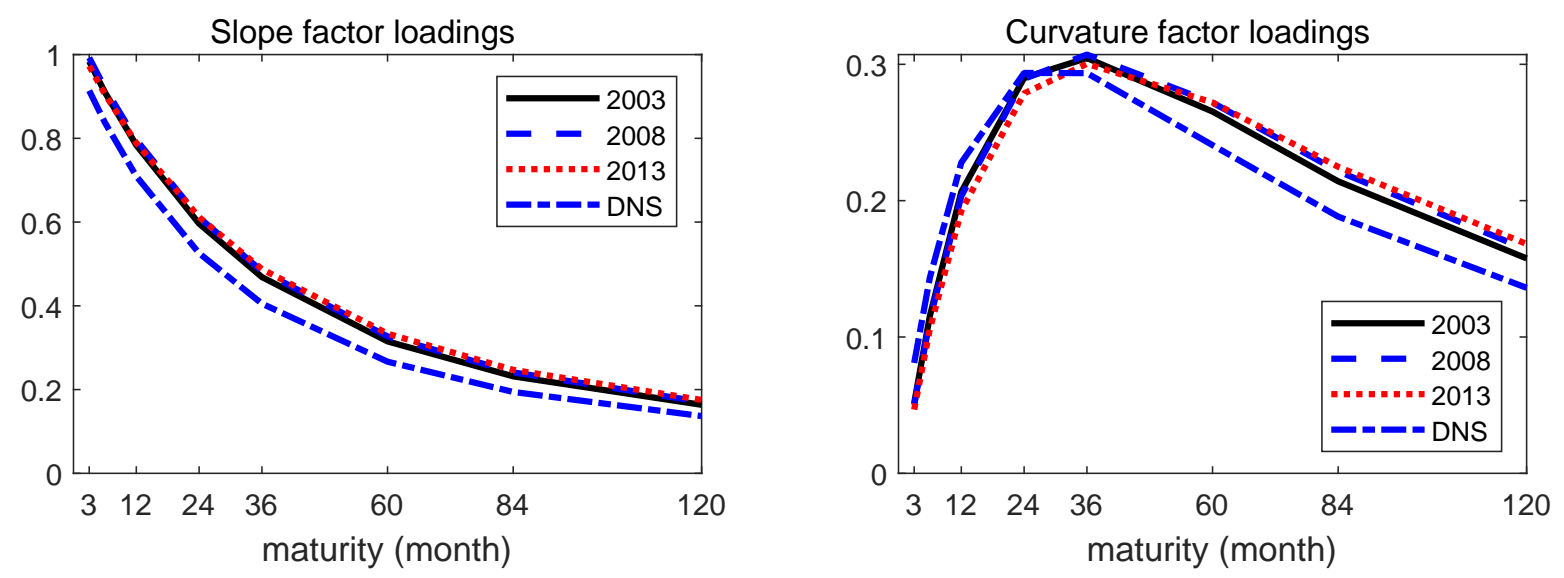

(b) recursive window

Note: The factor loadings for '2003', '2008', and '2013' indicate the posterior mean estimates from the AFNS model using the data up to December 2003, December 2008, and December 2013, respectively. The factor loading for 'DNS' indicates those based on the DNS model. Panel (a) presents the factor loading estimates from the rolling window regression, where the window size is 10 years, and panel (b) plots the estimates from the recursive window.

\section{Forecasting Results for the Full Evaluation Sample}

This section provides the MCS p-values and MSFEs for the full forecasting sample in Table D.1. The superiority of the RW model for the full evaluation sample is mainly driven by the unconventional monetary policy period. 
Table D.1: Full sample: Mean squared forecasting errors and MCS p-values

\begin{tabular}{|c|c|c|c|c|c|c|c|c|c|c|c|c|c|c|c|c|c|}
\hline & \multicolumn{2}{|c|}{3 months } & \multicolumn{2}{|c|}{6 months } & \multicolumn{2}{|c|}{12 months } & \multicolumn{2}{|c|}{24 months } & \multicolumn{2}{|c|}{36 months } & \multicolumn{2}{|c|}{60 months } & \multicolumn{2}{|c|}{84 months } & \multicolumn{2}{|c|}{120 months } & \multirow{2}{*}{$\begin{array}{c}\mathcal{M}_{90 \%} \\
\text { freq. }\end{array}$} \\
\hline & $p_{M C S}$ & MSFE & $p_{M C S}$ & MSFE & $p_{M C S}$ & MSFE & $p_{M C S}$ & MSFE & $p_{M C S}$ & MSFE & $p_{M C S}$ & MSFE & $p_{M C S}$ & MSFE & $p_{M C S}$ & MSFE & \\
\hline \multicolumn{18}{|c|}{ Single model } \\
\hline$N$ & 0.056 & 0.062 & 0.295 & 0.051 & 0.504 & 0.040 & 0.062 & 0.063 & 0.003 & 0.103 & 0.014 & 0.125 & 0.002 & 0.107 & 0.208 & 0.074 & 3 \\
\hline$A$ & 0.056 & 0.067 & 0.066 & 0.058 & 0.135 & 0.047 & 0.021 & 0.071 & 0.003 & 0.102 & 0.027 & 0.086 & 0.002 & 0.119 & 0.092 & 0.080 & 1 \\
\hline$R$ & 1.000 & 0.058 & 0.369 & 0.050 & 0.135 & 0.049 & 1.000 & 0.058 & 1.000 & 0.068 & 1.000 & 0.071 & 1.000 & 0.074 & 0.473 & 0.073 & 8 \\
\hline \multicolumn{18}{|c|}{ Equal weight } \\
\hline$N A_{E}$ & 0.014 & 0.081 & 0.051 & 0.063 & 0.083 & 0.050 & 0.021 & 0.077 & 0.003 & 0.122 & 0.014 & 0.119 & 0.002 & 0.141 & 0.092 & 0.085 & 0 \\
\hline$N R_{E}$ & 0.056 & 0.061 & 1.000 & 0.048 & 0.265 & 0.042 & 0.062 & 0.062 & 0.004 & 0.082 & 0.027 & 0.091 & 0.005 & 0.087 & 0.481 & 0.073 & 3 \\
\hline$A R_{E}$ & 0.025 & 0.068 & 0.066 & 0.059 & 0.070 & 0.052 & 0.021 & 0.069 & 0.004 & 0.086 & 0.055 & 0.076 & 0.002 & 0.096 & 0.092 & 0.079 & 0 \\
\hline$N A R_{E}$ & 0.011 & 0.094 & 0.051 & 0.077 & 0.070 & 0.067 & 0.010 & 0.093 & 0.003 & 0.121 & 0.014 & 0.112 & 0.002 & 0.135 & 0.026 & 0.099 & 0 \\
\hline \multicolumn{18}{|c|}{ Constant weight } \\
\hline$N A_{C}$ & 0.023 & 0.069 & 0.101 & 0.054 & 0.293 & 0.042 & 0.062 & 0.064 & 0.003 & 0.099 & 0.014 & 0.096 & 0.002 & 0.105 & 0.387 & 0.074 & 3 \\
\hline$N R_{C}$ & 0.056 & 0.063 & 0.321 & 0.050 & 0.293 & 0.041 & 0.062 & 0.064 & 0.003 & 0.094 & 0.014 & 0.109 & 0.002 & 0.097 & 0.395 & 0.073 & 3 \\
\hline$A R_{C}$ & 0.015 & 0.077 & 0.051 & 0.067 & 0.070 & 0.057 & 0.021 & 0.079 & 0.003 & 0.105 & 0.027 & 0.088 & 0.002 & 0.120 & 0.092 & 0.087 & 0 \\
\hline$N A R_{C}$ & 0.011 & 0.094 & 0.026 & 0.077 & 0.070 & 0.066 & 0.010 & 0.094 & 0.003 & 0.131 & 0.014 & 0.133 & 0.002 & 0.139 & 0.092 & 0.098 & 0 \\
\hline \multicolumn{18}{|c|}{ Markov-switching weight } \\
\hline$N A_{M S}$ & 0.014 & 0.092 & 0.006 & 0.081 & 0.070 & 0.067 & 0.021 & 0.087 & 0.003 & 0.111 & 0.027 & 0.093 & 0.002 & 0.115 & 0.092 & 0.085 & 0 \\
\hline$N R_{M S}$ & 0.056 & 0.061 & 0.380 & 0.049 & 1.000 & 0.040 & 0.062 & 0.061 & 0.004 & 0.086 & 0.014 & 0.096 & 0.005 & 0.089 & 1.000 & 0.073 & 3 \\
\hline$A R_{M S}$ & 0.015 & 0.075 & 0.051 & 0.061 & 0.083 & 0.050 & 0.021 & 0.075 & 0.004 & 0.093 & 0.027 & 0.082 & 0.002 & 0.110 & 0.092 & 0.083 & 0 \\
\hline \multirow[t]{4}{*}{$N A R_{M S}$} & 0.008 & 0.122 & 0.006 & 0.108 & 0.019 & 0.096 & 0.008 & 0.118 & 0.003 & 0.149 & 0.014 & 0.143 & 0.002 & 0.160 & 0.026 & 0.119 & 0 \\
\hline & \multicolumn{17}{|c|}{ (a) 1-month-ahead forecasts } \\
\hline & \multicolumn{2}{|c|}{3 months } & \multicolumn{2}{|c|}{6 months } & \multicolumn{2}{|c|}{12 months } & \multicolumn{2}{|c|}{24 months } & $36 \mathrm{n}$ & onths & $60 \mathrm{n}$ & onths & $84 \mathrm{n}$ & Ionths & 120 & lonths & $\mathcal{M}_{90 \%}$ \\
\hline & $p_{M C S}$ & MSFE & $p_{M C S}$ & MSFE & $p_{M C S}$ & MSFE & $p_{M C S}$ & MSFE & $p_{M C S}$ & MSFE & $p_{M C S}$ & MSFE & $p_{M C S}$ & MSFE & $p_{M C S}$ & MSFE & freq. \\
\hline Single $\mathrm{r}$ & odel & & & & & & & & & & & & & & & & \\
\hline$N$ & 0.141 & 0.408 & 1.000 & 0.362 & 1.000 & 0.334 & 0.038 & 0.391 & 0.012 & 0.458 & 0.011 & 0.459 & 0.049 & 0.396 & 0.042 & 0.300 & 3 \\
\hline$A$ & 0.044 & 0.482 & 0.062 & 0.474 & 0.050 & 0.440 & 0.002 & 0.494 & 0.003 & 0.549 & 0.129 & 0.379 & 0.003 & 0.496 & 0.004 & 0.365 & 1 \\
\hline$R$ & 1.000 & 0.374 & 0.394 & 0.378 & 0.200 & 0.359 & 1.000 & 0.347 & 1.000 & 0.364 & 1.000 & 0.332 & 1.000 & 0.313 & 0.439 & 0.285 & 8 \\
\hline Equal we & ight & & & & & & & & & & & & & & & & \\
\hline$N A_{E}$ & 0.026 & 0.545 & 0.051 & 0.496 & 0.050 & 0.445 & 0.003 & 0.491 & 0.003 & 0.566 & 0.011 & 0.503 & 0.003 & 0.524 & 0.004 & 0.376 & 0 \\
\hline$N R_{E}$ & 0.141 & 0.401 & 0.197 & 0.382 & 0.063 & 0.361 & 0.038 & 0.386 & 0.016 & 0.416 & 0.096 & 0.395 & 0.066 & 0.355 & 0.211 & 0.290 & 3 \\
\hline$A R_{E}$ & 0.141 & 0.446 & 0.094 & 0.442 & 0.050 & 0.421 & 0.005 & 0.445 & 0.006 & 0.474 & 0.096 & 0.384 & 0.015 & 0.427 & 0.004 & 0.346 & 1 \\
\hline$N A R_{E}$ & 0.141 & 0.460 & 0.163 & 0.438 & 0.063 & 0.409 & 0.033 & 0.436 & 0.012 & 0.466 & 0.096 & 0.389 & 0.034 & 0.420 & 0.023 & 0.330 & 1 \\
\hline Constant & weight & & & & & & & & & & & & & & & & \\
\hline$N A_{C}$ & 0.141 & 0.449 & 0.163 & 0.398 & 0.200 & 0.355 & 0.038 & 0.392 & 0.016 & 0.438 & 0.129 & 0.377 & 0.066 & 0.370 & 1.000 & 0.280 & 5 \\
\hline$N R_{C}$ & 0.141 & 0.413 & 0.163 & 0.386 & 0.063 & 0.362 & 0.033 & 0.413 & 0.012 & 0.465 & 0.011 & 0.454 & 0.049 & 0.399 & 0.042 & 0.310 & 2 \\
\hline$A R_{C}$ & 0.026 & 0.528 & 0.029 & 0.519 & 0.012 & 0.493 & 0.002 & 0.541 & 0.003 & 0.588 & 0.096 & 0.442 & 0.003 & 0.539 & 0.000 & 0.415 & 0 \\
\hline$N A R_{C}$ & 0.141 & 0.449 & 0.163 & 0.414 & 0.063 & 0.382 & 0.033 & 0.420 & 0.012 & 0.463 & 0.096 & 0.413 & 0.049 & 0.397 & 0.042 & 0.306 & 2 \\
\hline Markov-s & witching & weight & & & & & & & & & & & & & & & \\
\hline$N A_{M S}$ & 0.026 & 0.508 & 0.062 & 0.467 & 0.050 & 0.416 & 0.005 & 0.439 & 0.012 & 0.462 & 0.129 & 0.359 & 0.063 & 0.371 & 0.439 & 0.283 & 2 \\
\hline$N R_{M S}$ & 0.141 & 0.391 & 0.394 & 0.369 & 0.200 & 0.342 & 0.038 & 0.379 & 0.016 & 0.422 & 0.096 & 0.407 & 0.066 & 0.365 & 0.099 & 0.295 & 3 \\
\hline$A R_{M S}$ & 0.034 & 0.495 & 0.062 & 0.475 & 0.050 & 0.435 & 0.003 & 0.482 & 0.003 & 0.512 & 0.096 & 0.403 & 0.006 & 0.486 & 0.000 & 0.384 & 0 \\
\hline$N A R_{M S}$ & 0.088 & 0.463 & 0.163 & 0.435 & 0.063 & 0.402 & 0.033 & 0.431 & 0.008 & 0.467 & 0.096 & 0.399 & 0.049 & 0.404 & 0.042 & 0.317 & 1 \\
\hline
\end{tabular}

(b) 4-month-ahead forecasts 
Table D.1 (continued)

\begin{tabular}{|c|c|c|c|c|c|c|c|c|c|c|c|c|c|c|c|c|c|}
\hline & \multicolumn{2}{|c|}{3 months } & \multicolumn{2}{|c|}{6 months } & \multicolumn{2}{|c|}{12 months } & \multicolumn{2}{|c|}{24 months } & \multicolumn{2}{|c|}{36 months } & \multicolumn{2}{|c|}{60 months } & \multicolumn{2}{|c|}{84 months } & \multicolumn{2}{|c|}{120 months } & \multirow{2}{*}{$\begin{array}{c}\mathcal{M}_{90 \%} \\
\text { freq. }\end{array}$} \\
\hline & $p_{M C S}$ & MSFE & $p_{M C S}$ & MSFE & $p_{M C S}$ & MSFE & $p_{M C S}$ & MSFE & $p_{M C S}$ & MSFE & $p_{M C S}$ & MSFE & $p_{M C S}$ & MSFE & $p_{M C S}$ & MSFE & \\
\hline \multicolumn{18}{|c|}{ Single model } \\
\hline$N$ & 0.158 & 2.193 & 0.284 & 1.994 & 0.173 & 1.730 & 0.016 & 1.533 & 0.002 & 1.428 & 0.002 & 1.165 & 0.004 & 0.940 & 0.012 & 0.701 & 3 \\
\hline$A$ & 0.146 & 2.362 & 0.111 & 2.309 & 0.059 & 2.094 & 0.006 & 1.935 & 0.002 & 1.830 & 0.011 & 1.153 & 0.000 & 1.328 & 0.001 & 0.981 & 1 \\
\hline$R$ & 1.000 & 2.061 & 0.469 & 1.965 & 1.000 & 1.672 & 1.000 & 1.251 & 1.000 & 1.008 & 1.000 & 0.747 & 1.000 & 0.653 & 1.000 & 0.551 & 8 \\
\hline \multicolumn{18}{|c|}{ Equal weight } \\
\hline$N A_{E}$ & 0.146 & 2.407 & 0.144 & 2.267 & 0.110 & 1.986 & 0.016 & 1.768 & 0.002 & 1.665 & 0.002 & 1.272 & 0.001 & 1.204 & 0.004 & 0.893 & 3 \\
\hline$N R_{E}$ & 0.209 & 2.140 & 0.284 & 2.010 & 0.173 & 1.746 & 0.016 & 1.427 & 0.002 & 1.239 & 0.011 & 0.952 & 0.014 & 0.789 & 0.096 & 0.613 & 3 \\
\hline$A R_{E}$ & 0.209 & 2.168 & 0.212 & 2.093 & 0.110 & 1.860 & 0.016 & 1.568 & 0.002 & 1.379 & 0.011 & 0.931 & 0.004 & 0.925 & 0.009 & 0.709 & 3 \\
\hline$N A R_{E}$ & 0.270 & 2.135 & 0.284 & 2.051 & 0.173 & 1.827 & 0.016 & 1.554 & 0.002 & 1.351 & 0.011 & 0.917 & 0.008 & 0.857 & 0.071 & 0.645 & 3 \\
\hline \multicolumn{18}{|c|}{ Constant weight } \\
\hline$N A_{C}$ & 0.158 & 2.337 & 0.149 & 2.140 & 0.110 & 1.839 & 0.016 & 1.570 & 0.002 & 1.406 & 0.011 & 1.020 & 0.008 & 0.889 & 0.023 & 0.670 & 3 \\
\hline$N R_{C}$ & 0.209 & 2.163 & 0.284 & 2.018 & 0.173 & 1.775 & 0.016 & 1.546 & 0.002 & 1.411 & 0.011 & 1.133 & 0.004 & 0.922 & 0.012 & 0.694 & 3 \\
\hline$A R_{C}$ & 0.158 & 2.341 & 0.130 & 2.284 & 0.060 & 2.083 & 0.006 & 1.894 & 0.002 & 1.751 & 0.011 & 1.150 & 0.000 & 1.240 & 0.001 & 0.928 & 2 \\
\hline$N A R_{C}$ & 0.158 & 2.239 & 0.212 & 2.088 & 0.110 & 1.838 & 0.016 & 1.578 & 0.002 & 1.404 & 0.011 & 1.030 & 0.008 & 0.880 & 0.052 & 0.655 & 3 \\
\hline \multicolumn{18}{|c|}{ Markov-switching weight } \\
\hline$N A_{M S}$ & 0.065 & 2.422 & 0.144 & 2.252 & 0.110 & 1.945 & 0.016 & 1.647 & 0.002 & 1.446 & 0.011 & 0.977 & 0.008 & 0.887 & 0.023 & 0.667 & 1 \\
\hline$N R_{M S}$ & 0.270 & 2.078 & 1.000 & 1.933 & 0.257 & 1.694 & 0.016 & 1.454 & 0.002 & 1.314 & 0.011 & 1.048 & 0.008 & 0.862 & 0.039 & 0.656 & 3 \\
\hline$A R_{M S}$ & 0.158 & 2.311 & 0.149 & 2.205 & 0.110 & 1.925 & 0.016 & 1.689 & 0.002 & 1.502 & 0.011 & 0.979 & 0.001 & 1.081 & 0.004 & 0.829 & 2 \\
\hline$N A R_{M S}$ & 0.208 & 2.186 & 0.215 & 2.062 & 0.136 & 1.832 & 0.016 & 1.576 & 0.002 & 1.392 & 0.011 & 0.997 & 0.008 & 0.882 & 0.039 & 0.661 & 3 \\
\hline
\end{tabular}

(c) 12-month-ahead forecasts

Note: The last column shows the frequency of inclusion in the MCSs across different maturities for each model combination. 


\section{References}

Chib, S. 1998. "Estimation and comparison of multiple change-point models." Journal of Econometrics, 86: 221-241.

Chib, S., and S. Ramamurthy. 2010. "Tailored randomized-block MCMC methods for analysis of DSGE models." Journal of Econometrics, 155(1): 19-38.

Christensen, Jens H. E., Francis X. Diebold, and Glenn D. Rudebusch. 2011. "The affine arbitrage-free class of Nelson-Siegel term structure models." Journal of Econometrics, 164: $4-20$. 